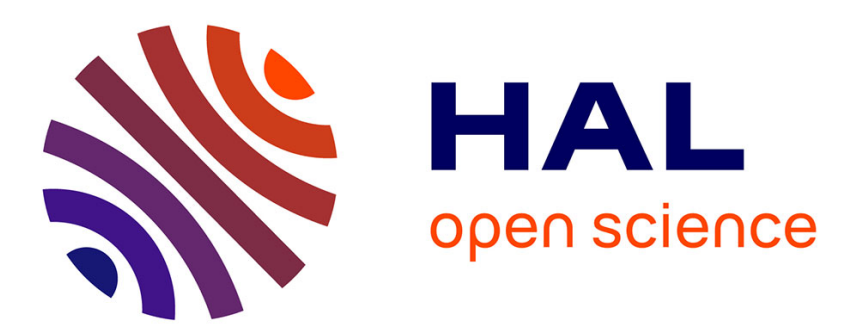

\title{
A mushy Earth's mantle for more than 500 Myr after the magma ocean solidification
}

Julien Monteux, D Andrault, M Guitreau, Henri Samuel, S Demouchy

\section{To cite this version:}

Julien Monteux, D Andrault, M Guitreau, Henri Samuel, S Demouchy. A mushy Earth's mantle for more than 500 Myr after the magma ocean solidification. Geophysical Journal International, 2020, 221 (2), pp.1165-1181. 10.1093/gji/ggaa064 . hal-03059716

\section{HAL Id: hal-03059716 https://hal.science/hal-03059716}

Submitted on 13 Dec 2020

HAL is a multi-disciplinary open access archive for the deposit and dissemination of scientific research documents, whether they are published or not. The documents may come from teaching and research institutions in France or abroad, or from public or private research centers.
L'archive ouverte pluridisciplinaire HAL, est destinée au dépôt et à la diffusion de documents scientifiques de niveau recherche, publiés ou non, émanant des établissements d'enseignement et de recherche français ou étrangers, des laboratoires publics ou privés. 


\title{
A mushy Earth's mantle for more than 500 Myr after the magma ocean solidification
}

\author{
J. Monteux, ${ }^{1}$ D. Andrault, ${ }^{1}$ M. Guitreau, ${ }^{1}$ H. Samuel ${ }^{\oplus 2}$ and S. Demouchy ${ }^{1,3}$ \\ ${ }^{1}$ Université Clermont Auvergne, CNRS, IRD, OPGC, Laboratoire Magmas et Volcans, F-63000 Clermont-Ferrand, France. E-mail: julien.monteux@uca.fr \\ ${ }^{2}$ Institut de Physique du Globe de Paris, Université Sorbonne Paris Cité, 75005 Paris, France \\ ${ }^{3}$ Géosciences Montpellier - Université Montpellier \& CNRS, F-34095 Montpellier, France
}

Accepted 2020 January 24. Received 2020 January 22; in original form 2019 July 17

\begin{abstract}
S U M MAR Y
In its early evolution, the Earth mantle likely experienced several episodes of complete melting enhanced by giant impact heating, short-lived radionuclides heating and viscous dissipation during the metal/silicate separation. After a first stage of rapid and significant crystallization (Magma Ocean stage), the mantle cooling is slowed down due to the rheological transition, which occurs at a critical melt fraction of 40-50\%. This transition first occurs in the lowermost mantle, before the mushy zone migrates toward the Earth's surface with further mantle cooling. Thick thermal boundary layers form above and below this reservoir. We have developed numerical models to monitor the thermal evolution of a cooling and crystallizing deep mushy mantle. For this purpose, we use a 1-D approach in spherical geometry accounting for turbulent convective heat transfer and integrating recent and solid experimental constraints from mineral physics. Our results show that the last stages of the mushy mantle solidification occur in two separate mantle layers. The lifetime and depth of each layer are strongly dependent on the considered viscosity model and in particular on the viscosity contrast between the solid upper and lower mantle. In any case, the full solidification should occur at the Hadean-Eoarchean boundary 500-800 Myr after Earth's formation. The persistence of molten reservoirs during the Hadean may favor the absence of early reliefs at that time and maintain isolation of the early crust from the underlying mantle dynamics.
\end{abstract}

Key words: Numerical modelling; Heat flow; Rheology: Mantle; Dynamics: convection currents, and mantle plumes; Heat generation and transport.

\section{INTRODUCTION}

After the giant impact which led to the formation of the EarthMoon system, the Earth's mantle was likely completely molten (e.g. Nakajima \& Stevenson 2015). During the subsequent Magma Ocean (MO) stage, the Earth's early mantle undergone a rapid global cooling until its melt fraction decrease to a critical value $\varphi_{c}$ $(\approx 40 \%)$ associated with a major increase of its viscosity (Solomatov 2007; Monteux et al. 2016). This step was followed by a slow cooling stage that triggered a complete crystallization of the silicate mantle (Solomatov 2007). This second cooling stage could have lasted hundreds of $\mathrm{Ma}$, or even a couple of $\mathrm{Ga}$ as its dynamics was governed by the rheology of the slowly deforming solid-like mantle, in contrast to the first one which was driven by the magma viscosity (Solomatov 2007; Ulvrová et al. 2012; Monteux et al. 2016).

Recent experimental results have shown that the upper mantle solidus is at lower temperature than previously expected for a chondritic composition (Andrault et al. 2018). According to this study, such a solidus associated with a hotter earlier mantle would enable the presence of a deep and persistent molten layer in the
Archean mantle. The progressive solidification of this melt layer could have enhanced the mechanical coupling between the lithosphere and the asthenosphere. Such a change might explain the transition from surface dynamics dominated by a stagnant lid to modern plate tectonics with deep-slab subductions. Assuming that the intersect between the mantle solidus and an adiabat temperature profile with a potential surface temperature corresponding to a surface melt fraction of $\varphi_{c} \approx 40 \%$ could constrain the depth of the bottom of the remaining partially molten layer, Solomatov ( 2007) obtained a depth $\approx 300 \mathrm{~km}$. In the case of bottom-up solidification of a mushy mantle, the depth of the last remaining partially molten layer should, hence, be smaller than $300 \mathrm{~km}$ and the full mantle crystallization should occur within $\approx 1 \mathrm{Ga}$ (Sleep et al. 2014).

The depth at which the full crystallization is reached is likely governed by (1) the solidus temperature which controls the depth and temperature of solidification, (2) the thickness of the top thermal boundary layer (TBL), where heat convecting from the deep mantle is transferred to the surface by conduction and (3) the temperature contrast on both sides of the TBL which controls the efficiency of heat evacuation. In the mushy regime, the mantle viscosity is a 
key parameter, which governs mantle dynamics and the formation of TBLs. This day viscosity of the Earth's mantle is difficult to constrain, particularly in the lower mantle (Č́žková et al. 2012), and the value of the viscosity of the Earth's early mantle prior to the occurrence of major differentiation events is even more hypothetical. Constraining the value of this physical quantity is of first importance, since deep mantle viscosity likely governs the initiation of major geological features, such as plate tectonics and mantle plumes (Sleep 2014; Foley et al. 2014).

We have developed a numerical model to monitor the cooling, and crystallization of an isochemical mantle, starting from a partially molten stage. We aim to characterize the influence of the viscosity of the solid early mantle on its cooling dynamics. In particular, we tested the impact of variation in activation energy and the viscosity prefactor, as well as monitored the cooling and crystallization processes to determine the solidification timescales and the depths at which the last melt fraction solidifies.

\section{MODEL}

We considered the cooling of a partially molten magma ocean with an initial depth of $2900 \mathrm{~km}$, which we modelled using a thermal evolution described below.

\subsection{Thermal evolution model}

\subsubsection{Heat transfer model}

We used a 1-D spherical approach (e.g. Abe 1997; Laneuville et al. 2018) accounting for turbulent convective heat transfer (e.g. Abe 1997; Monteux et al. 2016; Bower et al. 2018). This approach is relevant for the ranges of low viscosities and high Rayleigh numbers expected within a partially molten planetary mantle which are difficult to numerically resolve in 2-D and 3-D spatial domains. Indeed, even if $R a$ numbers are lower during the mushy stage than during the magma ocean stage, $R a$ numbers are still too high (up to $10^{30}$ ) to correctly solve the TBLs in such a dynamic reservoir. Moreover, molten reservoirs may survive during the early thermal evolution of the mushy mantle. In these regions, the melt fraction can reach values larger than $40 \%$ with very low associated viscosity of the mushy material, making the local Rayleigh number too high for 2-D or 3-D computational domains.

Our numerical model solves the following heat equation:

$\rho C_{p} \frac{\partial T}{\partial t}=\nabla \cdot(k \nabla T)+\rho H$,

where $\rho$ is the density, $C_{p}$ is the heat capacity, $T$ is the temperature and $H$ is the heat production from radiogenic sources. $k$ is an 'effective' conductivity defined as:

$k=k_{c}+k_{v}$,

with $k_{v}$ the effective conductivity relative to thermal convection of the mushy material is:

$k_{v}=\frac{F_{\text {conv }} L}{\Delta T}$

$F_{\text {conv }}$ is the convective heat flux accounting for thermal buoyancy, $L$ is the thickness of the Earth's mantle and $k_{c}$ the intrinsic thermal conductivity of the material $\left(k_{c}=5 \mathrm{~W} \cdot \mathrm{m}^{-1} \cdot \mathrm{K}^{-1}\right)$.
For mantle convection to occur, the temperature gradient must be larger than the adiabatic gradient:

$\left(\frac{\mathrm{d} T}{\mathrm{~d} r}\right)_{S}=\frac{-\alpha g T}{C_{p}}$.

When the temperature gradient is subadiabatic, the mantle heat is transported only by conduction, and $k=k_{c}$. When the temperature gradient is superadiabatic, the mantle is convecting. The convective heat flux $F_{\text {conv }}$ depends on the local Rayleigh number $R a$ :

$R a=\frac{\alpha g C_{p} \rho^{2} \Delta T L^{3}}{k_{c} \eta}$,

where $\alpha$ is the thermal expansion coefficient of the mushy material, $g$ is the gravitational acceleration assumed to be constant through the whole mantle and $\eta$ is the local dynamic viscosity. In eq. (5), $k_{c}$ is constant, $C_{p}$ is a function of the melt fraction, $\alpha$ and $\rho$ vary with depth and melt fraction. $\eta$ varies with depth, temperature and melt fraction. $\Delta T$ is the thermal driving force for the convection, therefore the temperature difference between the surface and the core-mantle boundary (CMB) minored by the increase of temperature along the mantle adiabat. Mantle dynamics and cooling is also governed by the Prandtl number, $P r$ :

$\operatorname{Pr}=\frac{\eta C_{p}}{k_{c}}$,

which is the ratio of the momentum diffusivity over the thermal diffusivity. $P r$ is calculated at each depth using the local viscosity value $\eta$. Depending on the values of $\operatorname{Pr}$ and $R a$, two flow regimes arise and as a consequence two convective heat fluxes:

(1) a soft turbulent regime where the corresponding convective heat flux is (Solomatov 2007; Monteux et al. 2016):

$F_{\text {conv }}=\frac{0.089 k_{c} \Delta T R a^{1 / 3}}{L}$ if $\operatorname{Ra}<10^{8} \operatorname{Pr}^{5 / 3}$;

(2) and a hard turbulent regime (following Solomatov 2007; Monteux et al. 2016) where:

$F_{\text {conv }}=\frac{0.22 k_{c} \Delta T R a^{2 / 7} \mathrm{Pr}^{-1 / 7}}{L}$ if $R a>10^{8} \mathrm{Pr}^{5 / 3}$.

In our numerical model, we compare the temperature gradient to the adiabatic gradient. If the temperature gradient is larger, $k_{v}$ is calculated according to eq. (3). If the temperature gradient is lower, $k=k_{c}$.

\subsubsection{Boundary and initial conditions}

The large impacts, radiogenic heating and the energy dissipated during metal-silicate separation control the early thermal state of the core. The core temperature at the end of the magma ocean stage is governed by the heat accumulated in this reservoir during its formation but also by the efficiency of the magma ocean to retain heat within the core by forming thick TBLs (Monteux et al. 2016). The core heat flow at the $\mathrm{CMB}$ can be expressed as:

$F_{\text {core }}=\frac{k_{c}\left(T^{\text {core }}-T_{\mathrm{CMB}}^{\text {mantle }}\right)}{\delta_{\mathrm{TBL}, \text { bot }}}$,

where $T^{\text {core }}$ is the average core temperature just below the CMB (i.e. here, a TBL within the core is not considered) and $T_{\mathrm{CMB}}^{\mathrm{mantle}}$ is the mantle temperature above the CMB. $\delta_{\mathrm{TBL} \text {, bot }}$ is the thickness of the $\mathrm{TBL}$ at the bottom of the mantle where the heat is extracted from the core by conduction. $T_{\mathrm{CMB}}^{\mathrm{mantle}}$ is calculated form eq. (1) whereas $T^{\text {core }}$ 
is obtained by the integration of the following differential equation:

$V_{\text {core }} \rho_{\mathrm{Fe}} C_{p, \mathrm{Fe}} \frac{\mathrm{d} T^{\text {core }}}{\mathrm{d} t}=S_{\text {core }} F_{\text {core }}$,

where $V_{\text {core }}$ is the core volume, $S_{\text {core }}$ is the core surface, $\rho_{\mathrm{Fe}}$ is the core density, $C_{p, \mathrm{Fe}}$ is the core heat capacity. This formulation does not consider the increase in adiabatic temperature within the core but allows following the evolution of core temperature right below the CMB as a function of time, based on the CMB heat flux. The error associated with this simplification (which in the case of an Earth-like body would amount to less than $10 \%$ ) is small compared to uncertainties in other model parameters.

The efficiency of mantle cooling also depends on the heat transfer at the surface. During the magma ocean cooling, heat is efficiently radiated toward space, but the formation of a primitive atmosphere may significantly slow down the cooling. With a primitive atmosphere composed of 300 bars $\mathrm{H}_{2} \mathrm{O}$ and 100 bars $\mathrm{CO}_{2}$ overlaying the magma ocean, Lebrun et al. (2013) estimated that the surface temperature remains constant throughout the entire duration of the mushy stage at $T_{\text {surf }} \approx 500 \mathrm{~K}$. Sleep et al. (2014) also showed that the surface temperature during the mushy stage was maintained at $\approx 500 \mathrm{~K}$ for 1000 bars and 100 bars atmospheres in equilibrium with bulk silicated magmas.

\subsubsection{TBLs parametrization}

Monteux et al. (2016) showed that the initial core heat can only be efficiently retained within the core when the bottom TBL thickness $\left(\delta_{\mathrm{TBL}, \text { bot }}\right)$ is larger than $\approx 100 \mathrm{~m}$. For $\delta_{\mathrm{TBL}, \text { bot }}<100 \mathrm{~m}$ the thermal coupling between the core and the MO is important and the core's heat is efficiently transferred to the mantle during the short timescales of the MO cooling. For $\delta_{\mathrm{TBL}, \text { bot }}<1 \mathrm{~m}$, the core rapidly cools down to $\approx 4400 \mathrm{~K}$, which corresponds to the core-mantle boundary temperature at a critical melt fraction $\varphi=\varphi_{\text {crit }}$. Actually, the thicknesses of both the bottom and top TBL are governed by the cooling dynamics of the mantle (Solomatov 1995). The formation of a TBL is induced by the velocity field decrease close to the boundary. In 1-D models, the TBL cannot form numerically by themselves because the velocity field is not calculated and, hence, it has to be parametrized. Moreover, as we consider a compressible fluid with properties changing with depth, the top and bottom TBL do not have the same thicknesses. In our models, we consider that the thermal boundary thickness scale as (Grott \& Breuer 2008):

$\delta_{\mathrm{TBL}}=L\left(\frac{R a_{\text {crit }}}{\overline{R a}}\right)^{1 / 3}$,

with $R a_{\text {crit }}=450$ (Choblet \& Sotin 2000) and $\overline{R a}$ is the Rayleigh number value calculated using eq. (5) and the characteristic parameters corresponding to either the top or the bottom of the magma ocean, for upper and lower TBL, respectively. It results in a TBL thicker at the top of the mantle, than at the bottom of the mantle. Strictly, the value of $R a_{\text {crit }}$ should be different when considering the upper or lower TBL (Thiriet et al. 2019). The value of 450 is adapted for the upper mantle. For the lower mantle, it should be expressed as a function of the internal Rayleigh number (Deschamps $\&$ Sotin 2000). We have implemented such a parametrization in our models. Our numerical tests (not shown here) show that the bottom TBL thickness derived from Deschamps \& Sotin (2000) leads to a decrease of the bottom TBL thickness, but does not change significantly the solidification depth and time scales. Hence, we used $R a_{\text {crit }}=450$ for both top and bottom TBL calculations. Within the TBLs, the heat is transferred by conduction and, again, $k=k_{c}$. In all the models presented here, the TBL thickness has a thickness larger than $10 \mathrm{~km}$, therefore given our 1-km grid spacing, at least 10 gridpoints are used to identify and characterize the heat transfer in the TBL.

\subsection{Geochemical model and derived parameters}

Despite the difficulty to characterize the chemical composition of the Earth's early mantle, a consensus has emerged that Earth's mantle should be of chondritic composition (e.g. Mc Donough \& Sun 1995; Javoy et al. 2010; Palme \& O’Neill 2014). Still, chondrites present a large diversity in major, minor and trace element compositions. According to several isotopic tracers, Earth has accreted from a large majority of building blocks typical of high-enstatite chondrites (EH, Javoy et al. 2010). Then, late-accretion processes and core-mantle differentiation (Rubie et al. 2011) have induced a drift of the bulk mantle composition to an $\mathrm{MgO}$-enriched composition, compared to EH (e.g. Mc Donough \& Sun 1995; Palme \& O’Neill 2014). In the following section, we detail our chemical model for the mushy mantle following the magma ocean stage.

\subsubsection{Radiogenic heating}

Short timescales inferred for the duration of the magma ocean stage appear comparable to the timescales for the decay of short-lived radionuclides such as ${ }^{26} \mathrm{Al}$. However, large bodies such as the protoEarth, or the Theia Earth's impactor, appeared only much later, from the accretion of pre-differentiated planetesimals. Therefore, only the long-lived radiogenic elements, such as ${ }^{238} \mathrm{U},{ }^{235} \mathrm{U},{ }^{232} \mathrm{Th}$ and ${ }^{40} \mathrm{~K}$ can provide heat at the long time scale corresponding to the cooling of the mushy mantle. In our models, we consider the radiogenic heating from these radionuclides in eq. (1) assuming that the abundance of these elements in the primitive mantle is similar to the concentration in EH-chondrites (Javoy 1999). The radiogenic heat production rate is computed as:

$H=\Sigma A_{i}[\mathrm{i}] H_{i} \exp \left(-\lambda_{i}\left(t-t_{0}\right)\right)$,

where the meaning of $A_{i}, E_{i}, H_{i}, \lambda_{i}$ is detailed in Table 1.

\subsubsection{Solidus and liquidus temperatures}

The chemical composition of the mantle governs its melting properties, based on its solidus and liquidus profiles. The latter plays a major role in the early thermal evolution of the magma ocean, because it defines the temperature and the depth at which crystallization starts. Laboratory experiments have constrained the liquidus and solidus of mantle-like material up to pressures compatible with the CMB conditions (Fiquet et al. 2010; Andrault et al. 2011). We performed calculations using the melting curves derived from chondritic-type mantle composition from Andrault et al. (2011, Fig. 1). The experimental solidus and liquidus profiles are fitted with a modified Simon and Glatzel equation (Simon \& Glatzel 1929). For pressures $P$ below $24 \mathrm{GPa}$, we use solidus and liquidus temperatures of chondritic mantle reported from Andrault et al. (2018):

$T_{\text {sol }}=1373 .\left(\frac{P}{0.82 \times 10^{9}}+1\right)^{(1 / 6.94)}$,
$T_{\text {liq }}=1983.4\left(\frac{P}{6.48 \times 10^{9}}+1\right)^{(1 / 5.35)}$. 
Table 1. Radiogenic heat sources and characteristics (from Javoy 1999).

\begin{tabular}{lcccc}
\hline Isotope/element & $\begin{array}{c}\text { Half-life } \\
\left(\lambda_{i}\right)(\mathrm{yr})\end{array}$ & $\begin{array}{c}\text { Heat production } \\
\text { per unit mass of } \\
\text { isotope } \\
\left(H_{i}\right)\left(\mathrm{W} \mathrm{kg}^{-1}\right)\end{array}$ & $\begin{array}{c}\text { Natural } \\
\text { Abundance } \\
\left(A_{i}\right)(\%)\end{array}$ & $\begin{array}{c}\text { Present-day } \\
\text { concentrations } \\
([\mathrm{i}])(\mathrm{ppm} \text { wt. })\end{array}$ \\
\hline${ }^{238} \mathrm{U}$ & $4.46 \times 10^{9}$ & $9.17 \times 10^{-5}$ & 99.28 & \\
${ }^{235} \mathrm{U}$ & $7.04 \times 10^{8}$ & $5.75 \times 10^{-4}$ & 0.72 & 0.20 \\
$\mathrm{U}$ & $1.4 \times 10^{11}$ & $2.56 \times 10^{-5}$ & 100 & 0.069 \\
${ }^{232} \mathrm{Th}$ & $1.26 \times 10^{9}$ & $2.97 \times 10^{-5}$ & 0.0117 & 270 \\
${ }^{40} \mathrm{~K}$ & & & & \\
$\mathrm{~K}$ & & & & \\
\hline
\end{tabular}

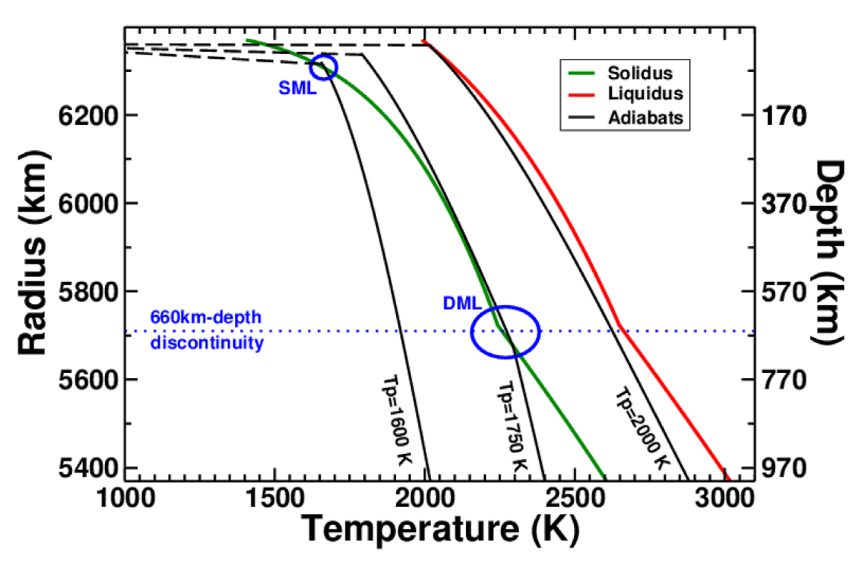

Figure 1. Solidus (green) and liquidus (red) (computed from eq. 12) as a function of the Earth's radius. Black solid lines show adiabatic temperature profiles (computed from eqs 4 and 18) with three different potential temperatures $(1600,1750$ and $2000 \mathrm{~K})$. Note that these three temperature profiles are arbitrary and do not result from our numerical model. The blue dashed line separates the upper and lower mantle. The dashed lines correspond to the hypothetic conductive temperature profiles in the top thermal boundary layer (i.e. recalculated at each step of our modelling procedure). The two ellipsoids illustrate critical points where deep and shallow last molten layers should solidify (SML, shallow mantle layer and DML, deep mantle layer).

For pressures larger than $P=24 \mathrm{GPa}$, we use results from Andrault et al. (2011):

$T_{\text {sol }}=1334.5\left(\frac{P}{9.63 \times 10^{9}}+1\right)^{(1 / 2.41)}$,

$T_{\text {liq }}=1862 \cdot\left(\frac{P}{21.15 \times 10^{9}}+1\right)^{(1 / 2.15)}$.

Mantle solidification may induce some chemical fractionation. In such case, the melting curves may evolve (Andrault et al. 2017). Major changes concern the liquidus temperature, which increases with the $\mathrm{MgSiO}_{3}$-content in the mantle. On the other hand, the mantle's solidus is almost independent of composition. These effects are not accounted in our study, because there is an insufficient knowledge on melting properties as a function of pressure, temperature and mantle composition.

\subsubsection{Thermodynamic parameters}

Thermodynamic parameters of the magma ocean depend of its chemical composition. Volumetric and elastic parameters of silicate liquids have been characterized up to a pressure of $140 \mathrm{GPa}$ using shock compression experiments (Mosenfelder et al. 2007, 2009;
Thomas et al. 2012; Thomas \& Asimow 2013). Here we assume a multicomponent system with a chondritic-type composition $(62 \%$ enstatite $+24 \%$ forsterite $+8 \%$ fayalite $+4 \%$ anorthite $+2 \%$ diopside). Using fourth-order Birch-Murnaghan/Mie-Grüneisen equation of state fits for molten silicate liquids from Thomas \& Asimow (2013), we obtain the melt density $\rho_{\mathrm{m}}$, the volumetric thermal expansion $\alpha$ as a function of pressure as well as the specific heat $C_{p}$ of the molten material for a chondritic multicomponent assemblage. The density of the solid phase is then calculated as:

$\rho_{s}=\rho_{m}+\Delta \rho$,

with $\Delta \rho$ being the density difference between solid and liquid phases which is fixed to $64 \mathrm{~kg} \mathrm{~m}^{-3}$ (Monteux et al. 2016).

For a partially molten material, the density $\rho^{\prime}$, the coefficient of volumetric thermal expansion $\alpha^{\prime}$ and the specific heat $C_{p}^{\prime}$ are given as follows (Solomatov 2007):

$\frac{1}{\rho^{\prime}}=\frac{1-\varphi}{\rho_{s}}+\frac{\varphi}{\rho_{m}}$

$\alpha^{\prime}=\alpha+\frac{\Delta \rho}{\rho\left(T_{\text {liq }}-T_{\text {sol }}\right)}$,

$C_{p}^{\prime}=C_{p}+\frac{\Delta H}{T_{\text {liq }}-T_{\text {sol }}}$,

where $\Delta H$ is the latent heat released during solidification, and $\varphi$ is the melt fraction:

$\varphi=\frac{T-T_{\mathrm{sol}}}{T_{\mathrm{liq}}-T_{\mathrm{sol}}}$.

\subsubsection{Adiabats}

In vigorously convecting systems such as magma oceans, the temperature distribution is nearly adiabatic (Solomatov 2007). For onephase systems, such as a completely molten or a completely solid layer, eq. (4) gives the equation for an adiabat. In two-phase systems (liquid + solid), the effects of phase changes need to be considered (Solomatov 2007). The equation for such adiabat follows:

$\left(\frac{\mathrm{d} T}{\mathrm{~d} r}\right)_{S}=\frac{-\alpha^{\prime} g T}{C_{p}^{\prime}}$.

This results in an increase of the adiabat gradient at depth where the two phases coexist, compared to the purely liquid or solid onephase adiabats (Solomatov 2007). Fig. 1 compares three adiabatic temperature profiles and the melting curves used in our study. The adiabatic temperature profiles are calculated by numerical integration of eqs (4) and (18) using a fourth-order Runge-Kutta method 
(Press et al. 1993). These adiabatic temperature profiles are used to calculate at each depth, and when it is super-adiabatic, the temperature difference $\Delta T$ from eq. (5).

\subsubsection{Assumptions}

During the solidification of the early mantle (i.e. the magma ocean and mushy mantle stages) chemical fractionation may occur between compatible and incompatible elements that partition preferentially into solid and liquid phases, respectively. Initially, the bridgmanite grains are denser than the liquid and they could fall toward the core-mantle boundary. Then, after a significant fraction of the MO is crystallized, the liquid could become denser as iron is a relatively incompatible element in mantle minerals. This could produce late mantle overturns (e.g. Boukaré et al. 2015). Such chemical differentiations could also induce heterogeneous distribution of radiogenic elements due to their incompatible behaviour. Still, the early chemical fractionation of the Earth's mantle history remains debated, based on contradictory geodynamical (Solomatov 2000) and geochemical (Mc Donough \& Sun 1995; Boyet \& Carlson 2005; Palme \& O'Neill 2014) arguments. Therefore, we do not consider chemical differentiation in the solidifying mushy mantle in this study. Hence, melting curves, density and concentration of radiogenic elements are considered unchanged along the cooling process.

\subsection{Viscosity model}

Viscosity governs mantle cooling dynamics, which is strongly dependent on the melt fraction $\varphi$. In our study we consider that $\varphi$ is a linear function of the temperature difference between the liquidus and the solidus (eq. 17). In the following section, we detail the parametrization used to compute the viscosity in our numerical models.

\subsubsection{Liquid fraction viscosity $(\varphi=1)$}

During the cooling of a mushy mantle, the melt fraction globally decreases; however, locally, mantle layers may remain largely molten for a long period of time. Therefore, a mushy mantle may locally be extremely turbulent because of the low viscosity of the molten mantle material (Cochain et al. 2017). For the fully molten mantle (i.e. when $\varphi=1$ ), we consider that its viscosity is equal to the viscosity reported for liquid $\mathrm{MgSiO}_{3}$ (Karki \& Stixrude 2010):

$$
\begin{aligned}
\eta= & \eta_{l}=\exp \left(-7.75+0.005 P(\mathrm{GPa})-0.00015 P(\mathrm{GPa})^{2}\right. \\
& \left.+\frac{5000+135 P(\mathrm{GPa})+0.23 P(\mathrm{GPa})^{2}}{T-1000}\right) .
\end{aligned}
$$

\subsubsection{Solid fraction viscosity $(\varphi=0)$}

The viscosity of the solid fraction within the early Earth's deep mantle is a key parameter, which governs its cooling efficiency during the mushy stage. However, such a quantity is poorly constrained for a chondritic mantle. Instead, the viscosity of a deep 'bridgmanite-bearing' mantle has become increasingly documented (e.g. Boioli et al. 2017; Reali et al. 2019). Due to the absence of seismic anisotropy in the current lower mantle, diffusion creep was generally considered to be the dominant deformation mechanism at these depths (e.g. Karato \& Li 1992), however, recent results advocate for diffusion-driven pure dislocation climb creep as a main deformation mechanism for bridgmanite (e.g. Boioli et al. 2017; Reali et al. 2019). During the early Earth's history, the mantle temperatures were hotter, and ionic diffusion (thus diffusion creep) is expected to have been even more important in the solid mantle fraction (e.g. Frost \& Ashby 1982) for both upper and lower mantle. Therefore, we assume here that the deformation of the interconnected solid phase occurs via diffusion creep only. We neglect the possible effect of polymineralic aggregates as one phase is expected to be volumetrically abundant (olivine or bridgmanite in the upper or lower mantle, respectively, see Ji et al. 2001; Huet et al. 2014). Hence for $\varphi=0$ :

$\eta=\eta_{s}=\frac{1}{A_{\text {diff }}} \exp \left(\frac{E_{\text {diff }}+P V_{\text {diff }}}{R T}\right)$,

with $P$ the pressure, $R$ the gas constant $\left(=8.314 \mathrm{~J} \mathrm{~K}^{-1} \mathrm{~mol}^{-1}\right)$ and $T$ the absolute temperature. $A_{\text {diff }}$ is the viscosity pre-factor, which includes grain-size sensitivity. Here the grain size is kept constant, as well as the grain size exponent (i.e. equals to 3 ). $E_{\text {diff }}$ is the activation energy, and $V_{\text {diff }}$ is the activation volume for diffusion creep.

In addition, we considered $E_{\text {diff, }}, V_{\text {diff }}$ and $A_{\text {diff }}$ values based on two requirements: (1) the values of the rheological parameters must be compatible with those derived from experiments (e.g. Hirth \& Kohlstedt 2003 for dry olivine/upper mantle, and Xu et al. 2011 for the bridgmanite/lower mantle), (2) the calculated viscosity profile corresponding to a realistic present-day Earth mantle geotherm [for an adiabatic temperature profile with $T_{p}=1600 \mathrm{~K}$ (Tackley 2012) and references therein] and a PREM pressure profile in eq. (19b), must be compatible with viscosity profiles constrained by geoid and postglacial rebound [see Čížková et al. (2012) and references therein, Fig. 2 and Table 2].

In our calculations, we also investigate the potential role of the upper mantle, which presents a different mineralogy and, therefore, distinct rheological properties. For the sake of simplicity, we did not implement a transition zone (composed of wadsleyite $(410-520 \mathrm{~km})$ and ringwoodite $(520-660 \mathrm{~km})$. The mineralogical transition from olivine to bridgmanite significantly increases the viscosity of the mantle, which in turn could affect the ability of the mantle to lose its primordial heat. The rheological parameters for the upper mantle (whenever considered) are listed in Table 2.

\subsubsection{Viscosity of the partially molten mantle $(0 \leq \varphi \leq 1)$}

During the solidification of the mushy mantle, the fraction of solid material increases until reaching a threshold $\left(\varphi=\varphi_{\text {crit }}\right)$, which separates the turbulent regime from viscous regime (Solomatov 2015). For $\varphi_{\text {crit }}<\varphi<1$, the viscosity of the highly molten material scales with the viscosity of the molten mantle $\eta_{l}$ (Roscoe 1952):

$\eta=\frac{\eta_{l}}{\left(1-\left(\frac{1-\varphi}{1-\varphi_{\text {crit }}}\right)\right)^{2.5}}$.

As soon as the melt fraction threshold is reached at any mantle depth, the cooling efficiency of the primitive mantle significantly reduces, even if the mantle remains partially molten at other depths (Monteux et al. 2016). In a mushy mantle context where most of the material is solid, the viscosity is still strongly influenced by the fraction of the molten material $\varphi$. For $0<\varphi<\varphi_{\text {crit }}$ the partially molten viscosity scales with the solid mantle viscosity $\eta_{s}$ :

$\eta=\eta_{s} \exp \left(-\alpha_{n} \varphi\right)$ 

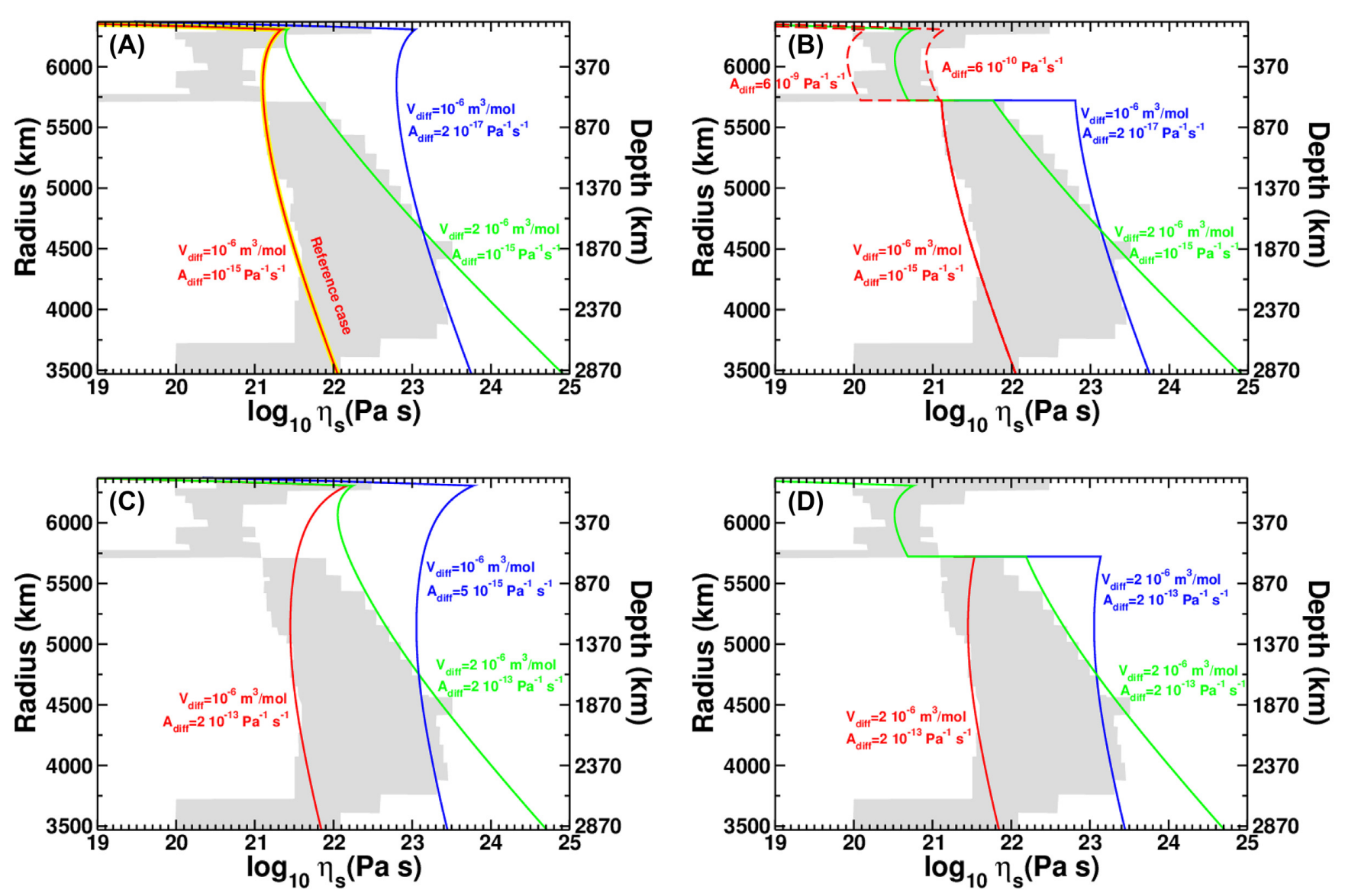

Figure 2. The different mantle viscosity profiles considered in our models for the solid phase, computed using eq. (19b). Upper panels, $E_{\text {diff }}=200 \mathrm{~kJ}$ mol ${ }^{-1}$ (with reference case highlighted in yellow) and lower panels $E_{\text {diff }}=300 \mathrm{~kJ} \mathrm{~mol}^{-1}$. Grey domain viscosity models from geoid inversion and post-glacial rebound [Č́žková et al. (2012) and references therein]. Left-hand frame: no viscous dichotomy between the upper and lower mantle is considered. Right-hand frame: when a different upper mantle is considered. We performed calculations for $A_{\text {diff }}$ and $V_{\text {diff }}$ ranging from $2 \times 10^{-17}$ to $2 \times 10^{-13} \mathrm{~Pa}^{-1} \mathrm{~s}^{-1}$ and $10^{-6}$ to $2 \times 10^{-6} \mathrm{~Pa}^{-1} \mathrm{~s}^{-1}$, respectively (Table 2). In the B-frame, we have also studied the influence of the upper mantle viscosity with $A_{\text {diff }}$ ranging from $6 \times 10^{-10}$ to $6 \times 10^{-9} \mathrm{~Pa}^{-1} \mathrm{~s}^{-1}$. The viscosity profiles (red, green and blue lines) are calculated considering an adiabatic temperature profile with $T_{p}=1600 \mathrm{~K}$ from the surface of the Earth to the CMB, thus neglecting the presence of top and bottom boundary layers for the figure readability.

Table 2. Values used in eq. (19b) to calculate the solid mantle viscosity.

\begin{tabular}{|c|c|c|c|}
\hline \multicolumn{4}{|c|}{ Lower 'bridgmanite-like' mantle rheology: } \\
\hline$A_{\text {diff }}$ & $\begin{array}{l}\text { Pre-exponential parameter for diffusion } \\
\text { creep }\end{array}$ & $2 \times 10^{-17}$ to $2 \times 10^{-13}$ & $\mathrm{~Pa}^{-1} \mathrm{~s}^{-1}$ \\
\hline$E_{\text {diff }}$ & Activation energy for diffusion creep & $\begin{array}{l}200 \text { (Čížková et al. 2012) } \\
300 \text { (Xu et al. 2011) }\end{array}$ & $\mathrm{kJ} \mathrm{mol}^{-1}$ \\
\hline$V_{\text {diff }}$ & Activation volume for diffusion creep & $1 \times 10^{-6}$ to $2 \times 10^{-6}$ & $\mathrm{~m}^{3} \mathrm{~mol}^{-1}$ \\
\hline \multicolumn{4}{|c|}{ Upper mantle rheology (dry olivine, grain size $=15 \mu \mathrm{m})$ : } \\
\hline$A_{\text {diff }}$ & $\begin{array}{l}\text { Pre-exponential parameter for diffusion } \\
\text { creep }\end{array}$ & $6 \times 10^{-9}$ to $6 \times 10^{-10}$ & $\mathrm{~Pa}^{-1} \mathrm{~s}^{-1}$ \\
\hline$E_{\text {diff }}$ & Activation energy for diffusion creep & 375 (Hirth \& Kohlstedt 2003) & $\mathrm{kJ} \mathrm{mol}^{-1}$ \\
\hline$V_{\text {diff }}$ & Activation volume for diffusion creep & $2.5 \times 10^{-6}$ (Hirth \& Kohlstedt 2003) & $\mathrm{m}^{3} \mathrm{~mol}^{-1}$ \\
\hline
\end{tabular}

with $\alpha_{n}$ the coefficient in melt fraction-dependent viscosity. The latter equals 26 for deformation via olivine diffusion creep mechanism under anhydrous conditions (Mei et al. 2002).

\subsection{Numerical model}

We model the thermal evolution of a 2900-km-thick isochemical silicate mantle overlying an iron core by solving for the conservation of energy (eq. 1) in a 1-D, spherically symmetric domain (with a radius ranging from 3500 to $6400 \mathrm{~km}$ ). To this end, we used a modified version of the numerical model developed in Monteux et al. (2016). Eq. (1) is discretized using a semi-implicit predictor-corrector Finite Difference scheme, of second-order in both space and time (Press et al. 1993). Our numerical scheme was successfully benchmarked against steady and unsteady analytical solutions for diffusion problems (Crank 1975). We have also successfully benchmarked our physical model with 3-D spherical calculations at both steady and transient states from the models developed by Wagner et al. (2019) 
Table 3. Parameter values used to calculate the viscosity of the lower mantle. Viscosity layering means that we consider an upper mantle in our model.

\begin{tabular}{lcccc}
\hline Series \# & Viscosity layering & $E_{\text {diff }}\left(\mathrm{kJ} \mathrm{mol}^{-1}\right)$ & $V_{\text {diff }}\left(\mathrm{m}^{3} \mathrm{~mol}^{-1}\right)$ & $A_{\text {diff }}\left(\mathrm{Pa}^{-1} \mathrm{~s}^{-1}\right)$ \\
\hline $\mathbf{1}$ & No & 200 & $1 \times 10^{-6}-2 \times 10^{-6}$ & $2 \times 10^{-17}-1 \times 10^{-15}$ \\
$\mathbf{2}$ & Yes & 200 & $1 \times 10^{-6}-2 \times 10^{-6}$ & $2 \times 10^{-17}-1 \times 10^{-15}$ \\
$\mathbf{3}$ & No & 300 & $1 \times 10^{-6}-2 \times 10^{-6}$ & $5 \times 10^{-15}-2 \times 10^{-13}$ \\
$\mathbf{4}$ & Yes & 300 & $1 \times 10^{-6}-2 \times 10^{-6}$ & $5 \times 10^{-15}-2 \times 10^{-13}$ \\
\hline
\end{tabular}

considering a relatively lower $R a$ number and a smaller viscosity contrast (see the Appendix). The mantle is discretized using 2900 equally spaced gridpoints resulting in a constant spatial resolution $\delta r=1 \mathrm{~km}$. The variable time step is set as $\delta t=\min \left(\delta r^{2} / \kappa(r)\right)$, where $\kappa(r)=k /(\rho C p)$ is the effective diffusivity. The boundary conditions in our models are those described in Section 2.1.2: isothermal at the surface with $T_{\text {surf }}=500 \mathrm{~K}$ and variable heat flux accounting for heat transfer between the core and the mantle at the CMB. In all our models, the core temperature below and just above the CMB are initialized to the same value $\left(T_{0 \text {,core }}=4370 \mathrm{~K}\right)$.

\section{RESULTS: COOLING AND SOLIDIFICATION DYNAMICS}

\subsection{A reference case}

We followed the thermal evolution of a deep mushy ocean with an initial temperature profile corresponding to a melt fraction of $40 \%$ throughout the whole mantle. As a reference case, we considered the chondritic-type mantle from Series 1 with $A_{\text {diff }}=10^{-15} \mathrm{~Pa}^{-1} \mathrm{~s}^{-1}$ and $V_{\text {diff }}=10^{-6} \mathrm{~m}^{3} \mathrm{~mol}^{-1}$ through the whole mantle (see Table 3 ). This reference case represents a lower bound in terms of viscosity (Fig. 2). The temperature initially decreases rapidly from the surface where heat is efficiently extracted by conductive cooling, and where a thin TBL initially forms (Fig. 3). In the deepest part of the mantle, the temperature profile bends towards an adiabatic temperature profile, which is more vertical than the solidus profile. As a consequence, the solidification front starts from the lowermost mantle. After $100 \mathrm{Myr}$, most of the lower mantle temperatures lie below the solidus, nevertheless two molten reservoirs remain (named hereafter SML and DML). Fig. 3 (bottom panels) shows that $270 \mathrm{Myr}$ after the beginning of our simulation, the deeper one (DML) is located at a depth centred at $650 \mathrm{~km}$, and the depth of shallower one (SML) ranges between 20 and $60 \mathrm{~km}$. Full solidification of DML occurs prior to that of SML. Finally, after $900 \mathrm{Myr}$ of cooling, the entire temperature profile is below the solidus, but remains super adiabatic,
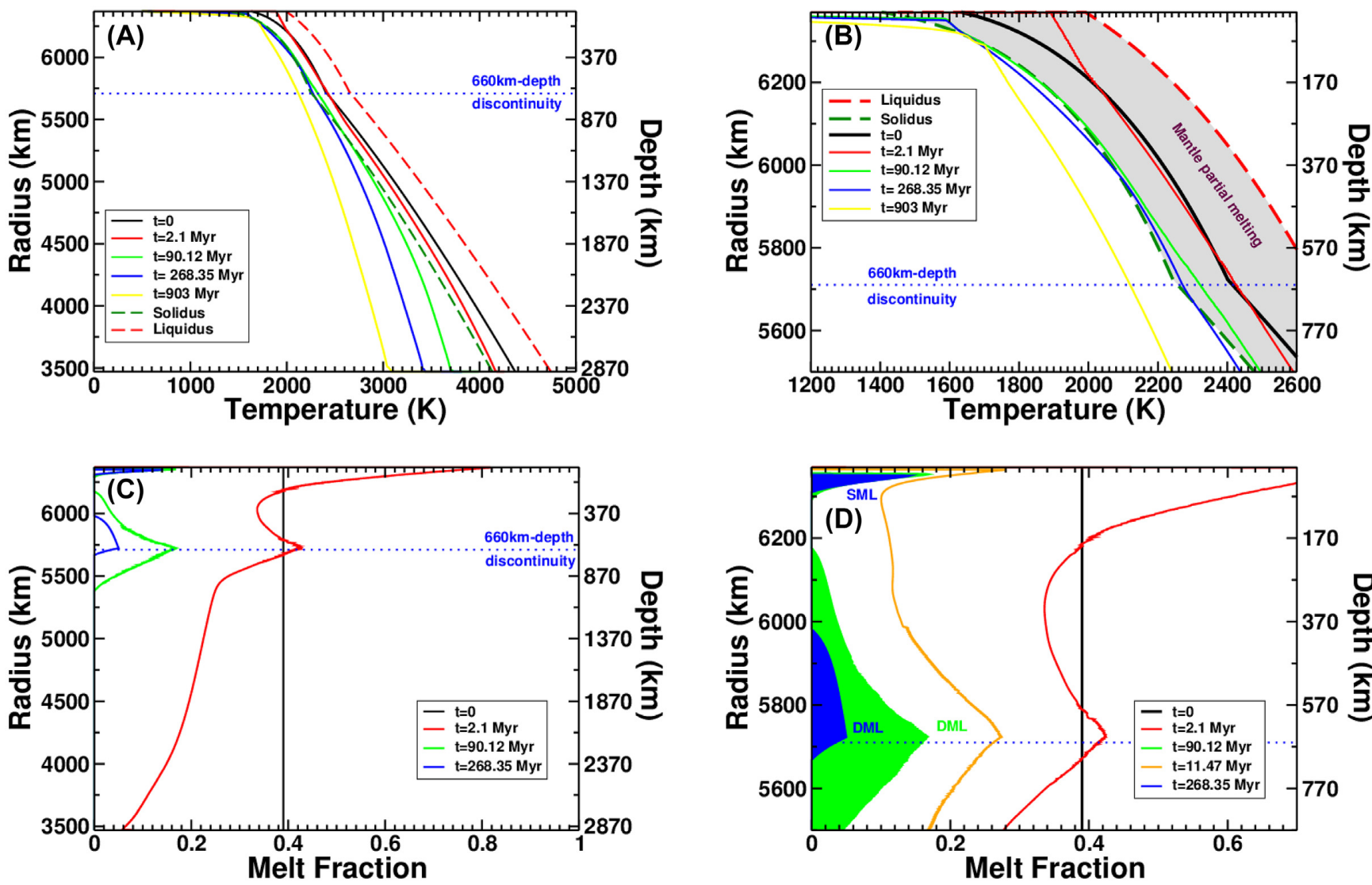

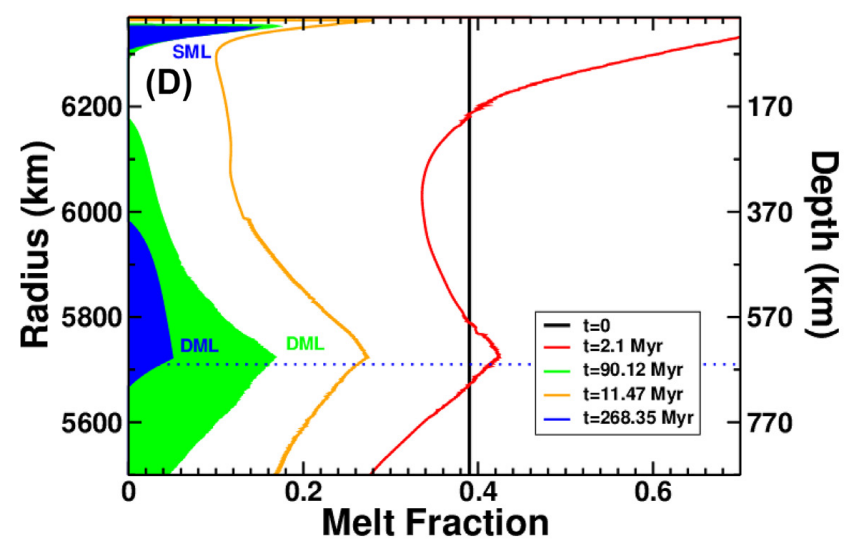

Figure 3. Upper panels: temperature time evolution as a function of depth. Lower panels: melt fraction time evolution as a function of depth. In this reference case (Series $1, A_{\text {diff }}=10^{-15} \mathrm{~Pa}^{-1} \mathrm{~s}^{-1}$ and $V_{\text {diff }}=10^{-6} \mathrm{~m}^{3} \mathrm{~mol}^{-1}$ ), no dichotomy in the viscosity model is considered between the upper and lower mantle. The blue dashed line separates the upper and lower mantle. The right-hand panels represent close-up views of the left-hand panels. When $t>90 \mathrm{Myr}$, the partially molten layer is separated in 2 layers: SML and DML. 

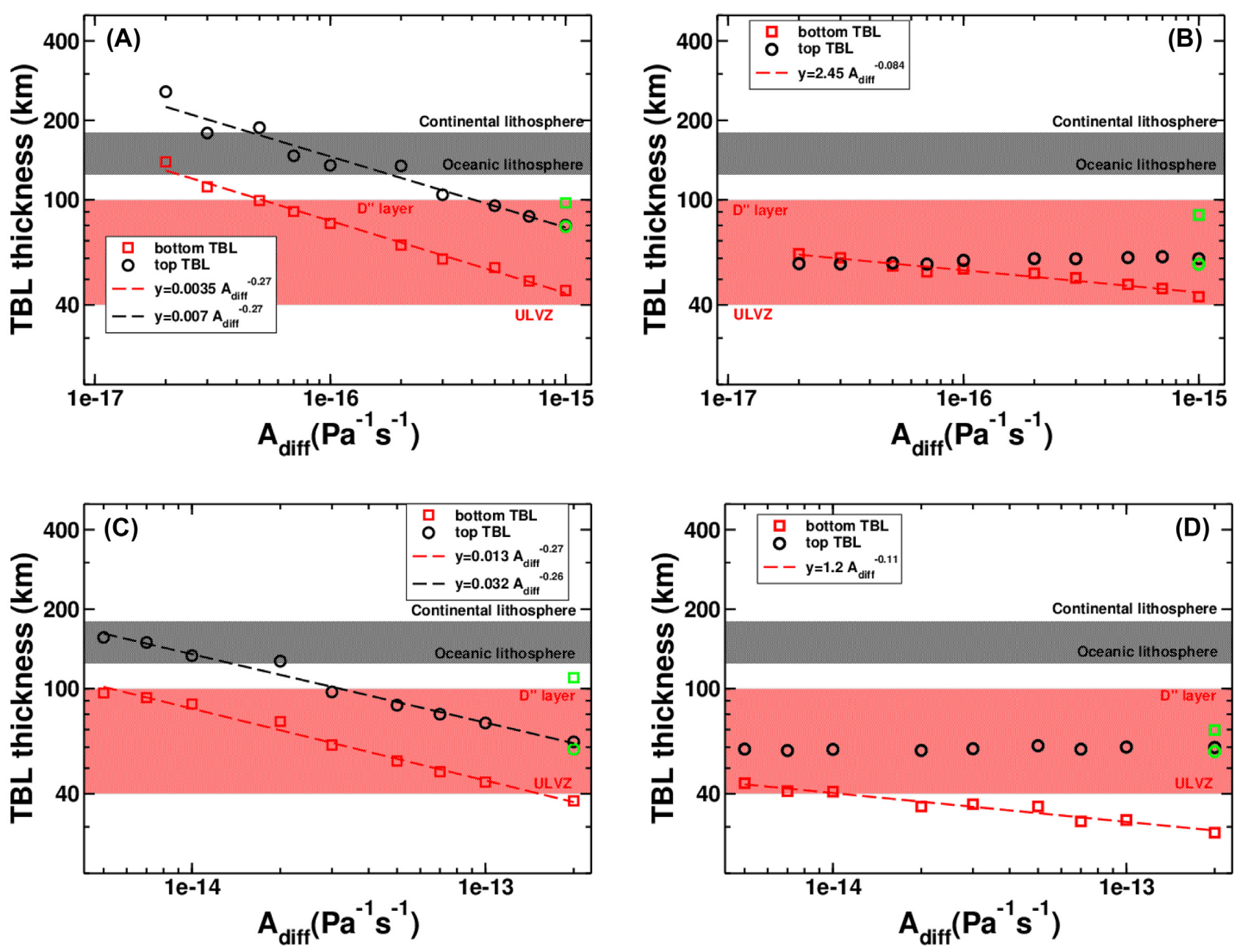

Figure 4. Thickness of the top (circles) and bottom (squares) thermal boundary layer when the mushy mantle is fully solidified as a function of $A_{\mathrm{diff}}$ and $E_{\mathrm{diff}}$ (i.e. $E_{\text {diff }}=200 \mathrm{~kJ} \mathrm{~mol}^{-1}$ for top figures or $E_{\text {diff }}=300 \mathrm{~kJ} \mathrm{~mol}^{-1}$ for bottom figures). The A, B, C, D panels correspond to Series $1,2,3,4$, respectively (see Tables 2 and 3 for complete set of parameter values). The cases with $V_{\text {diff }}=10^{-6} \mathrm{~m}^{3} \mathrm{~mol}^{-1}$ are illustrated with red (bottom TBL) and black (top TBL) symbols and cases with $V_{\text {diff }}=2 \times 10^{-6} \mathrm{~m}^{3} \mathrm{~mol}^{-1}$ are illustrated with green symbols. Dashed lines represent power law fits to the thermal evolution data points.

especially in the mid-top mantle. This solidification timescale is in good agreement with the timescale proposed by Solomatov (2000), where the complete crystallization of the shallow early mantle could last more than $10^{8} \mathrm{yr}$.

\subsection{Influence of the viscosity parameters on the mushy mantle solidification}

\subsubsection{TBL thicknesses}

From the initial thermal state, two TBLs rapidly form above and below the convecting portion of the mantle. Upon cooling, the Rayleigh number within the convecting mantle decreases and the two boundary layers thicken following the scaling used in eq. (10). Therefore, the thickness of the boundary layers scales with $R a^{-1 / 3}$ and as a consequence scales with $\eta^{1 / 3}$ and $A_{\text {diff }}^{-1 / 3}$. In Fig. 4, we plotted both the bottom (red) and top (black) boundary layer thicknesses at the end of the mushy stage (i.e. as soon as the mantle reaches complete solidification) as a function of the viscosity exponential pre-factor ( $\left.A_{\text {diff }}\right)$ and for two different values of the activation energy $\left(E_{\text {diff }}\right)$ and activation volume $\left(V_{\text {diff }}\right)$. Our results show that the evolution of the TBL thickness is strongly dependent on the value of the activation energy $\left(E_{\text {diff }}=200\right.$ or $\left.300 \mathrm{~kJ} \mathrm{~mol}^{-1}\right)$ and on $A_{\text {diff }}$ as illustrated in Fig. 4. For Series 1 (Fig. 4a), both the top and bottom boundary layer thicknesses scale with $A_{\text {diff }}^{-0.27}$, which is close to the theoretical scaling of $A_{\text {diff }}^{-1 / 3}$ for an entirely solid mantle. This indicates that the viscosity of the solid mantle governs the thickness of the two TBL. At the end of the mushy stage, the top boundary layer thickness ranges between 80 and $250 \mathrm{~km}$, whereas the bottom boundary layer thickness ranges between 45 and $140 \mathrm{~km}$. For Series 3 (Fig. 4c), the behaviour of the bottom TBL thickness is similar to the Series 1 cases. The bottom TBL thickness decreases as $A_{\text {diff }}^{-0.26}$ with corresponding values ranging from $\approx 40$ to $\approx 100 \mathrm{~km}$, and the top TBL thickness decreases as $A_{\text {diff }}^{-0.27}$, with corresponding values ranging from $\approx 60$ to $\approx 160 \mathrm{~km}$.

When an upper mantle is considered (Figs $4 \mathrm{~b}$ and d), the influence of the lower mantle viscosity on both the top and bottom TBL thicknesses vanishes. The bottom TBL thickness decreases as $A_{\text {diff }}^{-0.084}$ for Series 2 and as $A_{\text {diff }}^{-0.11}$ for Series 4 . For both values of $E_{\text {diff }}$ we used for the lower mantle viscosity, the top TBL thickness decreases to a value of $\approx 60 \mathrm{~km}$ at the end of the mushy stage, independently of the value of $E_{\text {diff. }}$. 

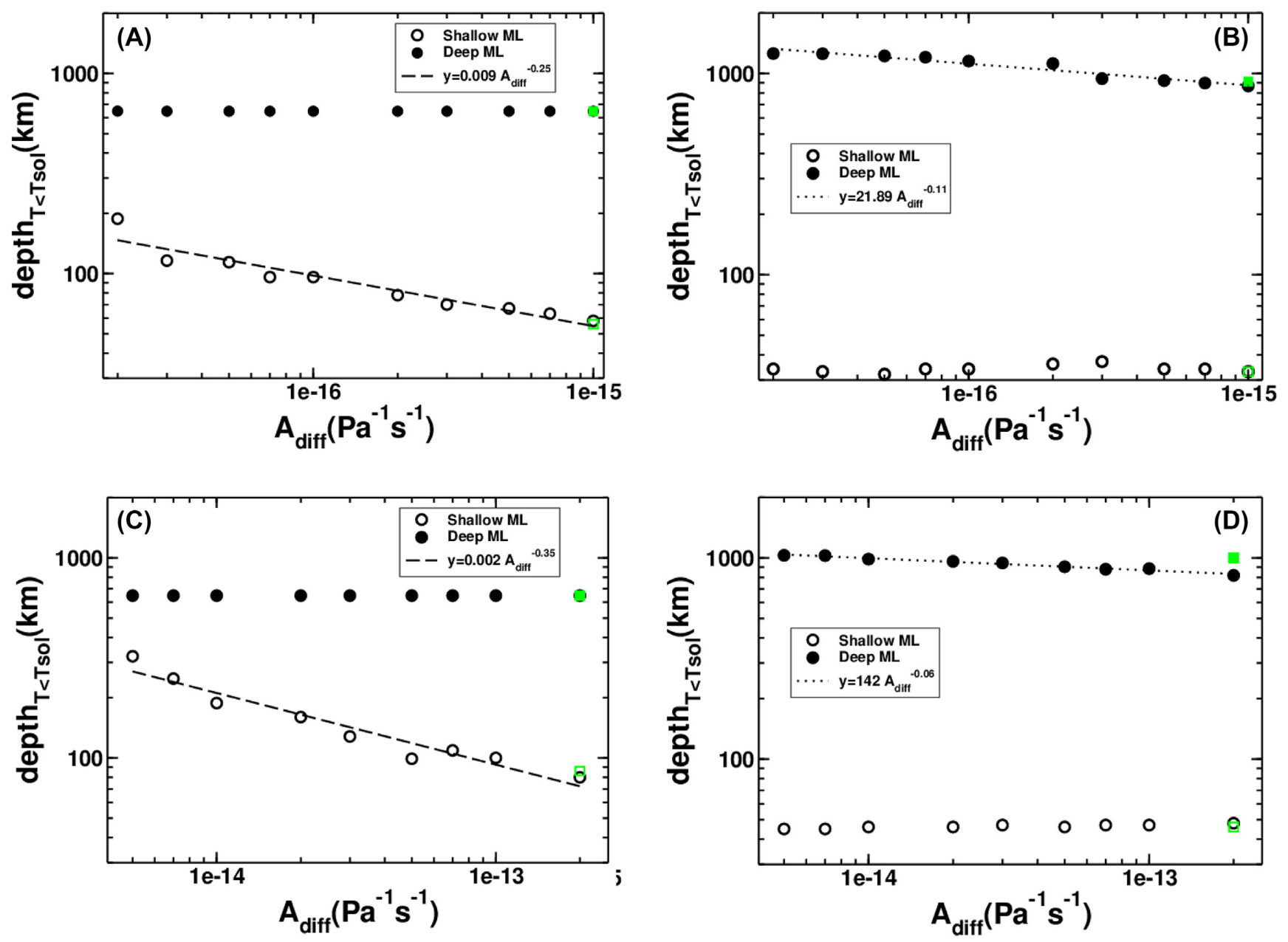

Figure 5. Depth at which the last layers of partially molten material solidify as a function of $A_{\text {diff }}$. Open symbols represent the solidification depth of the upper molten layer (SML) whereas solid symbols illustrate the solidification depth of the lower molten layer (DML) (See also Figs 3c and d). The a, b, c, d panels correspond to Series 1, 2, 3, 4, respectively (see Tables 2 and 3 for parameter values). The cases with $V$ diff $=10^{-6} \mathrm{~m}^{3} \mathrm{~mol}^{-1}$ are in black symbols and cases with $V_{\text {diff }}=2 \times 10^{-6} \mathrm{~m}^{3} \mathrm{~mol}^{-1}$ are in green symbols. Dashed and dotted lines represent power law fits of the numerical data for SML and DML, respectively.

Also, the top TBL thickness is weakly dependent on the value of $V_{\text {diff, }}$ as shown in Fig. 4. However, this parameter strongly influences the bottom TBL thickness. Indeed, increasing $V_{\text {diff }}$ from $1 \times 10^{-6}$ to $2 \times 10^{-6} \mathrm{~m}^{3} \mathrm{~mol}^{-1}$ results into a viscosity increase by at least a factor 2 to 3 for both $E_{\text {diff }}=200 \mathrm{~kJ} \mathrm{~mol}^{-1}$ and $E_{\text {diff }}=300 \mathrm{~kJ}$ $\mathrm{mol}^{-1}$ cases, and for cases considering an upper mantle and its influence in rheology or not. This result illustrates the influence of $V_{\text {diff }}$ on the viscosity, and can be understood when comparing the red and green viscosity profiles from Fig. 2 . As the value of $V_{\text {diff }}$ governs how the viscosity increases with depth from a reference value, increasing $V_{\text {diff }}$ does not change significantly the viscosity close to the Earth's surface. However, increasing $V_{\text {diff }}$ increases significantly the viscosity in the lowermost mantle, leading to a significant thickening of the TBL above the core mantle-boundary. In our models, right after the solidification of the molten layers (SML and DML), the viscosity above the bottom TBL for cases with $V_{\text {diff }}=2 \times 10^{-6} \mathrm{~m}^{3} \mathrm{~mol}^{-1}$ is larger than the viscosity above the bottom TBL for $V_{\text {diff }}=1 \times 10^{-6} \mathrm{~m}^{3} \mathrm{~mol}^{-1}$ by a factor $10-30$. This important increase in the lower mantle viscosity explains the increase in TBL thickness illustrated in Fig. 4 for our range of $V_{\text {diff }}$ values as the TBL scales with $\eta^{1 / 3}$.

\subsubsection{Depth of final melt layer}

During the cooling and the solidification of the mushy mantle, the melt fraction decreases from a global value of 0.4 to 0 (Figs $3 \mathrm{c}$ and $d$ ). Depending on the solid viscosity parameters used for the early mushy mantle, two layers can remain molten before full solidification: a deep one (DML) and a shallower one (SML, see also Fig. 3). The depths at which the two last layers of melt solidify as a function of $A_{\text {diff }}$ for two different values of $E_{\text {diff }}$ and $V_{\text {diff }}$ is reported in Fig. 5. This figure shows that the crystallization mechanism strongly depends on the presence of a viscosity dichotomy between the upper and lower mantle. When no dichotomy is considered (Figs 5a and c), the behaviour is similar for $E_{\text {diff }}=200 \mathrm{~kJ}$ $\mathrm{mol}^{-1}$ and $E_{\text {diff }}=300 \mathrm{~kJ} \mathrm{~mol}^{-1}$. For both $E_{\text {diff }}$ values, the solidification depth of the upper molten layer (SML) decreases as the viscosity decreases (scaling with $A_{\text {diff }}^{-0.25}$ and $A_{\text {diff }}^{-0.35}$, respectively) whereas the solidification depth of the deep molten layer (DML) is constant and equals $660 \mathrm{~km}$ (i.e. the depth of the transition between the upper and lower mantle). In the later case, the transition is not the consequence of rheological properties but is related to the change of the solidus slope (eqs (12a) and (12c) and Fig. 3), which is steeper in the lower mantle than in the upper mantle. These 

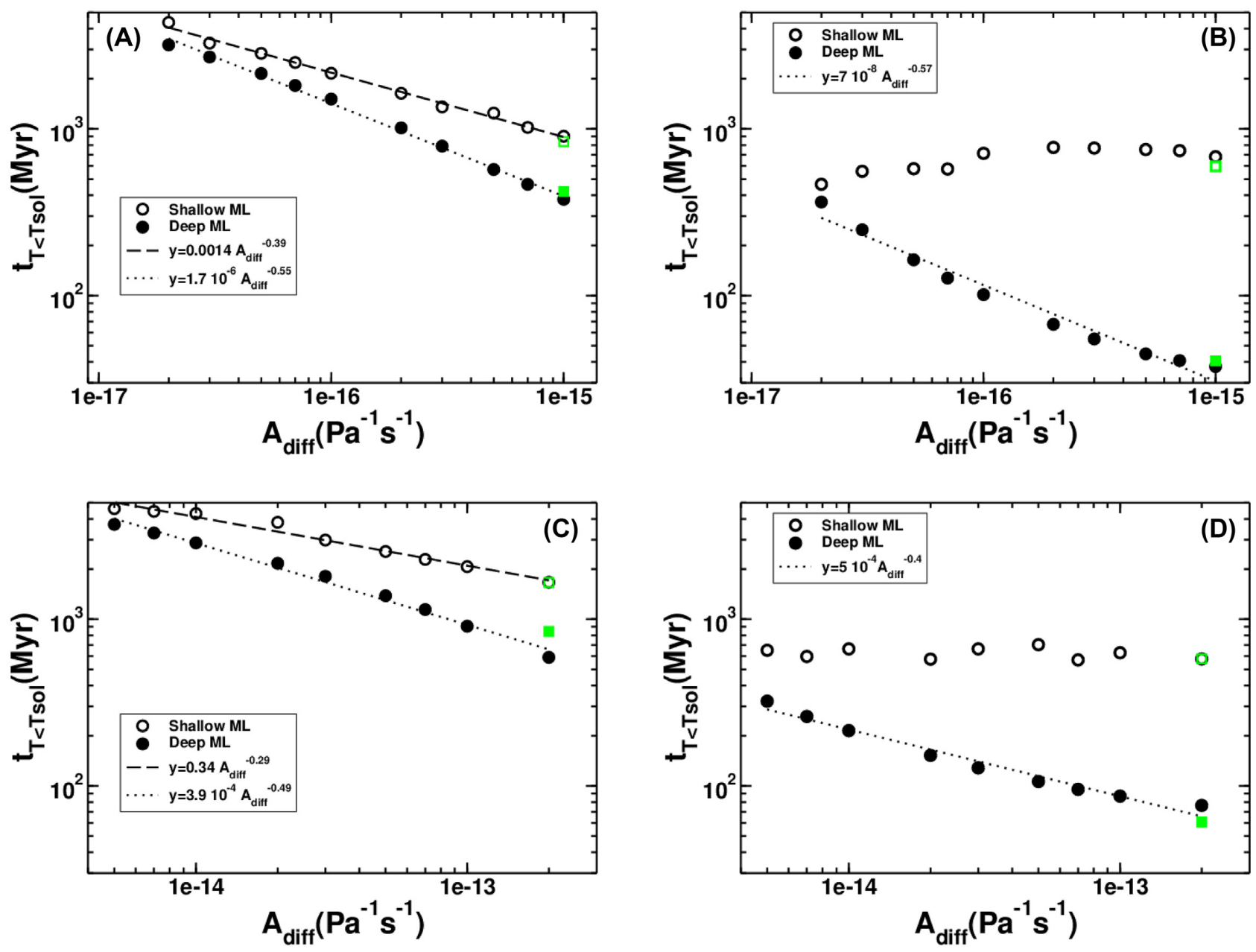

Figure 6. Duration for full solidification of the mushy mantle (initially with $\varphi=0.4$ ). Open symbols represent the solidification time of the upper molten layer (SML) whereas solid symbols illustrate the solidification time of the lower molten layer (DML). The a, b, c, d panels correspond to Series 1, 2, 3, 4, respectively (see Tables 2 and 3 for parameter values). The cases with $V_{\text {diff }}=10^{-6} \mathrm{~m}^{3} \mathrm{~mol}^{-1}$ are illustrated with black symbols and cases with $V_{\text {diff }}=2 \times 10^{-6} \mathrm{~m}^{3} \mathrm{~mol}-1$ are illustrated with green symbols. Dashed and dotted lines represent power law fits of the numerical data for SML and DML, respectively.

changes in the melting properties with depth coupled with the slope of the temperature profile computed from our models explain this particular behaviour. In these cases, the depth of the deep molten layer is insensitive to the value of the viscosity parameters.

However, a mineralogical dichotomy between the upper and lower mantle is likely to appear rapidly during the solidification of the mushy mantle, due to the high-pressure polymorphism. When considering rheologically distinct upper and lower mantles (Figs $5 \mathrm{~b}$ and d), the solidification depth of the deep molten layer is no longer tied to a depth of $660 \mathrm{~km}$, but now depends on the viscosity of the lower mantle. The depth at which DML solidifies decreases when $A_{\text {diff }}$ increases (i.e. when the lower mantle viscosity decreases) and scales with $A_{\text {diff }}^{-(0.06-0.1)}$ (Figs $5 \mathrm{~b}$ and d). This results in a deep solidification stage occurring at depth decreasing from 1250 to $800 \mathrm{~km}$ when $A_{\text {diff }}$ increases within the range envisioned in our study (i.e. when the deep mantle viscosity decreases). In contrast, the depth of final upper molten layer SML remains nearly constant $(\approx 30-50 \mathrm{~km})$ for the whole range of lower mantle viscosities considered in Fig. 5. This illustrates the fact that the depth at which the last upper layer of melt solidifies is not governed by the viscosity of the lower mantle but rather by the rheological properties of the upper mantle (we tested this hypothesis in Section 3.2.4).

\subsubsection{Mushy stage timescale}

The influence of $A_{\text {diff }}$ on the time required to fully solidify a partially molten mantle and for two different values of $E_{\text {diff }}$ and $V_{\text {diff }}$ is reported in Fig. 6. A quick inspection of eq. (1) indicates that this solidification timescale should be inversely proportional to the convective heat flux $F_{\text {conv }}$. In the hard-turbulent regime, this term scales as $\eta^{-3 / 7}$ whereas in the soft-turbulent regime, this term scales as $\eta^{-1 / 3}$. The eq. (19b) implies that an increase of either $E_{\text {diff }}$ or $V_{\text {diff }}$ yields an increase of the viscosity. On the contrary, an increase of $A_{\text {diff }}$ yields a decrease of the solid viscosity at given $P$ and $T$ conditions scaling with $A_{\text {diff }}^{-1}$. Consequently, if the viscosity of its solid fraction governs the characteristic solidification timescale, this time should scale as $A_{\text {diff }}^{-n}$ with $n$ ranging between $1 / 3$ and $3 / 7$. This is confirmed by our numerical results (Figs $6 \mathrm{a}$ and $\mathrm{c}$ ). The time required for the upper molten layer (SML) to fully solidify scales with $A_{\text {diff }}^{-0.39}$ for Series 1 (Fig. 6a) and with $A_{\text {diff }}^{-0.29}$ for Series 3 (Fig. 6c). For the lower molten layer (DML), the influence of mantle viscosity is even stronger and the time required for DML to fully solidify scales with $A_{\text {diff }}^{-0.55}$ for Series 1 (Fig. 6A) and with $A_{\text {diff }}^{-0.49}$ for Series 3 (Fig. 6c).

When no upper/lower mantle dichotomy is considered, the duration of the complete mushy mantle solidification ranges between 

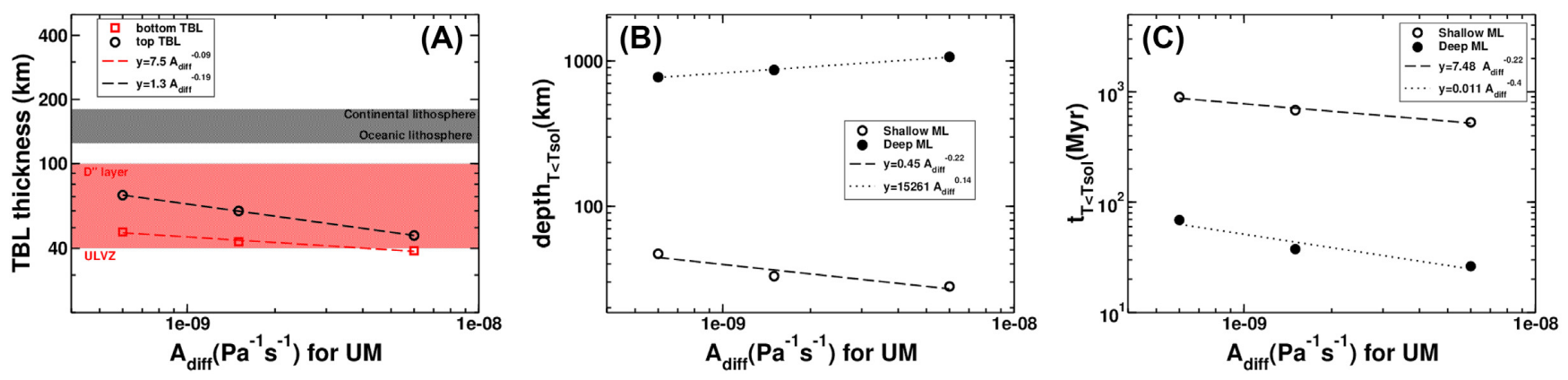

Figure 7. TBL thickness (a), depth at which the last layers (upper and lower) of partially molten material solidify (b) and time to fully solidify the last layers (upper and lower) of partially molten (c) as a function of the value of $A_{\text {diff }}$ in the upper mantle. In these figures, $A_{\text {diff }}=10^{-15} \mathrm{~Pa}^{-1} \mathrm{~s}^{-1}, E_{\mathrm{diff}}=200 \mathrm{~kJ}$ mol ${ }^{-1}$ and $V_{\text {diff }}=10^{-6} \mathrm{~m}^{3} \mathrm{~mol}^{-1}$ in the lower mantle whereas $E_{\text {diff }}=375 \mathrm{~kJ} \mathrm{~mol}^{-1}$ and $V_{\text {diff }}=2.5 \times 10^{-6} \mathrm{~m}^{3} \mathrm{~mol}^{-1}$ in the upper mantle. Open symbols represent the solidification time of the upper molten layer (SML) whereas solid symbols illustrate the solidification time of the lower molten layer (DML). Dashed and dotted lines represent power law fits of the numerical data for SML and DML, respectively.

900 Myr and 4.4 Gyr for Series 1 (Fig. 6a). For Series 3 (Fig. 6c), the solidification duration ranges between 1.6 and 4.6 Gyr. Our results also show that the solidification of the deeper DML occurs prior to that of the shallower SML, with times ranging between $375 \mathrm{Myr}$ and $3.2 \mathrm{Gyr}$ for $E_{\text {diff }}=200 \mathrm{~kJ} \mathrm{~mol}^{-1}$ or between $590 \mathrm{Myr}$ and $3.7 \mathrm{Gyr}$ for $E_{\text {diff }}=300 \mathrm{~kJ} \mathrm{~mol}^{-1}$. Fig. 6 also shows that our solidification timescale is nearly insensitive to the value of $V_{\text {diff }}$.

When considering an upper mantle rheologically different from the lower mantle (Figs $6 \mathrm{~b}$ and d), several changes occur, compared to models without viscous dichotomy. The solidification timescale for the upper molten layer (SML) is less affected by changes in the value of $A_{\text {diff }}$ than DML. Thus, the time required to fully solidify the whole mantle (SML and DML) exhibits a narrower range of values (between 460 and 770 Myr for Series 2 and between 570 and $700 \mathrm{Myr}$ for Series 4). On the contrary, the solidification time of the deeper molten layer DML strongly depends on the viscosity of the lower mantle and scales with $A_{\text {diff }}^{-0.57}$ for Series 2 and with $A_{\text {diff }}^{-0.4}$ for Series 4. Again, the solidification time of DML is faster than SML (between 37 and 365 Myr for Series 2 or between 76 and $322 \mathrm{Myr}$ for Series 4). Our results suggest that the solidification of the SML (i.e. the final episode of solidification of the early mantle in our models) is weakly sensitive to the viscosity of the lower mantle but is mostly governed by the viscosity of the upper mantle. On the other hand, the solidification time of the DML is in comparison faster, and the viscosity of the lower mantle governs the time delay. This is certainly related to the relatively low upper mantle viscosity used in this calculation (see Fig. 2).

\subsubsection{Influence of the upper mantle viscosity}

We then investigated the influence of the upper mantle viscosity on the characteristic time and length scales of mushy terrestrial mantle crystallization. Thus we considered the reference case detailed in Fig. 3 with a dichotomy in the viscosity between the upper and lower mantle. In this section, we consider constant values for $A_{\text {diff }}, E_{\text {diff }}$ and $V_{\text {diff }}$ for the lower mantle, and we used three different values for $A_{\text {diff }}$ for the upper mantle ranging between $6 \times 10^{-10}$ and $6 \times 10^{-9}$ $\mathrm{Pa}^{-1} \mathrm{~s}^{-1}$.

The results given in Fig. 7 show that the viscosity of the upper mantle influences both the shallow characteristic time and length scales. We recall here that increasing the value of $A_{\text {diff }}$ results in a viscosity decrease. Fig. 7(a) shows that both the top and the bottom TBL thicknesses now decrease when $A_{\text {diff }}$ in the upper mantle increases. The top TBL is more sensitive to variations in the $A_{\text {diff }}$ values in the upper mantle than the bottom TBL (power exponent -0.19 compared to -0.9 in top and bottom TBL, respectively). In Fig. 7(b), the results show that the depth at which the shallow molten layer SML solidifies decreases with $A_{\text {diff }}^{-0.22}$, whereas the depth at which the deep molten layer DML solidifies increases with $A_{\text {diff }}^{0.14}$. This means that decreasing the upper mantle viscosity (i.e. increasing $A_{\text {diff }}$ in the upper mantle) favors a deeper solidification of DML, while favoring the solidification of SML closer to the surface. Finally, results from Fig. 7(c) shows that both the time at which SML and DML solidify decrease when increasing $A_{\text {diff }}$ in the upper mantle. Interestingly, the viscosity of the upper mantle has a stronger influence on the solidification time for the DML than on the shallow SML (power exponent -0.4 compared to -0.22 ). Hence, by controlling the heat loss in the shallower part of the early Earth, the upper mantle viscosity strongly influences the characteristic solidification time and length scales.

Figs 5(b), (d) and 6(b), (d) show that, when a dichotomy in viscosity is considered, the depth and solidification time of the shallow molten layer are weakly dependent on the viscosity of the deep mantle. However, Fig. 7 illustrates that the viscosity of the upper mantle plays a key role on the time and depth of solidification of the shallow molten layer and is more important than the influence of the lower mantle on this time. Concerning the DML, a decrease of either upper or lower mantle viscosity leads to a decrease of the solidification time of this layer. Nevertheless, this time is more influenced by the viscosity of the deep mantle than by the viscosity of the upper mantle (power exponent -0.57 compared to -0.4 ). An interesting behaviour arises from the depth at which the deep molten layer DML solidifies. Indeed, Figs 5(b)-(d) shows that this depth decreases when $A_{\text {diff }}$ in the lower mantle increases (i.e. when the viscosity decreases) for a fixed value of $A_{\text {diff }}$ in the upper mantle. On the contrary, the depth at which DML solidifies increases when $A_{\text {diff }}$ in the upper mantle increases for a fixed value of $A_{\text {diff }}$ in the lower mantle. Our results show that the rheological parameters of both the upper and lower mantle govern the deep processes of solidification in the lower mantle, whereas the shallower solidification processes are governed only by the properties of the upper mantle.

\subsubsection{Summary}

We have developed a numerical approach to constrain the characteristic depth and time of solidification of a mushy mantle. We have identified two persistent molten layers (SML) and (DML). We show that the cooling and solidification dynamics are very sensitive to the 
Rayleigh number that increases with decreasing viscosity. Hence, an increase of the pre-exponential factor $A_{\text {diff }}$ (i.e. a decrease of the viscosity) systematically leads to a decrease of the TBL thicknesses (in agreement with eq. 10) and as a consequence to the depth of solidification of the last layer of molten material. As higher $R a$ values lead to a more efficient cooling of the early mantle, the timescale of complete solidification of the mantle also decreases with decreasing $A_{\text {diff. }}$ Within a moderately convecting viscous mantle, the TBL thickness and the cooling timescale are expected to scale with $R a^{-1 / 3}$ while within a turbulent reservoir they are expected to scale with $R a^{-2 / 7}$. In our models were important changes in the parameters occur with temperature, pressure and melt fraction, the value of the exponent in the power law is slightly different (from -0.25 to -0.55 when no viscous dichotomy is considered) but the behaviour is similar.

We have characterized the influence of the solid mantle viscosity with or without a rheological contrast between the upper and lower mantle. Our parametrical study shows that the viscosity of the deep mantle influences the solidification of the DML. This result is not surprising since the bottom TBL thickness is related to the viscosity of the deep material. Hence, one can expect that the solidification characteristics (depth and time scales) of the DML to be strongly influenced by the values of $A_{\text {diff }}$ in the lower mantle. Our results show that the same reasoning can be applied to the solidification characteristics of the SML that is governed by the values of $A_{\text {diff }}$ in the upper mantle.

Our results show that the viscosity of the upper mantle affects the DML solidification characteristics. This feature illustrates that the upper mantle governs the global mantle dynamics by acting as a thermal blanket that reduces the efficiency of heat loss. Hence, a decrease in the upper mantle viscosity leads to an increase of the surface heat flux, to a more vigorous internal convection associated with a thinner bottom TBL (Fig. 7a), and to a more rapid solidification (Fig. 7c). Conversely, the viscosity of the lower mantle does not influence significantly the SML solidification characteristics (Figs 4-6, right-hand panels). Again, this illustrates that the viscosity of the upper mantle mostly controls the cooling and solidification dynamics. A low viscosity lower mantle enhances the heat transfer from the core toward the mantle but the mantle heat loss is limited by the viscous properties of the upper mantle.

\section{DISCUSSION}

\subsection{Geological constraints}

A mineralogical dichotomy and a subsequent transition of the viscous behaviour between the upper and lower mantle are likely to appear rapidly during the solidification of the mushy mantle. In the following discussion we only consider the results from the models that account for a viscous dichotomy between the upper and lower mantle (i.e. left-hand column, b and d graphics in Figs 4-6). Our model results show that the top melt layer (SML) crystallizes at the Hadean-Eoarchean boundary (500-800 Myr after Earth's formation; Fig. 6), regardless of the model, and the crystallization proceeds at relatively shallow depths of 35-45 km (Fig. 5). On the contrary, the bottom melt layer (DML) crystallizes at deeper levels (800-1000 km; Fig. 5) and earlier (40-400 Myr after Earth's formation; Fig. 6). If the upper mantle viscosity is considered separately, these time and depth estimates are only slightly decreased or increased (Fig. 7).
The presence of molten material and the resulting rheological weakening may have profound effect on the evolution of the early crust, on its ability to deform and on how orogens develop (Sawyer et al. 2011). The persistence of a melt layer at shallow depth during the Hadean and its final crystallization around the Hadean-Eoarchean boundary could prevent the formation of elevated orogenic formations due to fast isostatic compensation of any created reliefs and development of large-scale tectonic fault and shear-zones. The absence of reliefs would, in turn, result in a water-world with most of the Earth being covered by shallow water. Major faults and shear-zones could represent pathways for liquid water to penetrate to lower crustal levels and, in turn, induce intense hydrothermal activity. In addition, this weak layer at the depth of the lower crust could possibly isolate the crust from the underlying mantle. Doglioni et al. (2011) proposed that a stable partial melt layer between the asthenosphere and the lithosphere could induce an effective viscous decoupling between the two layers and explain the lifetime of cratonic roots. At the Hadean-Eoarchean, the viscous coupling between the mantle and the crust could have induced the beginning of large-scale Hadean crust reworking and the formation of stable Archean crustal blocks. The persistence of SML could, hence, account for the absence of Hadean crustal fragments in geological record and at the beginning of the Archean geological record. They are solid outputs from our geodynamic models and, therefore, they should have affected the dynamics of our planet early in its history. Hence, linking the timing of major differentiation events in the geological record with SML and DML crystallization could help understanding early shallow processes.

Little is known about the Hadean period since we do not have the rock record at the Hadean-Eoarchean boundary (e.g. Goodwin 1996; Guitreau et al. 2012). Yet, some detrital zircon crystals, formed during the Hadean, survived until today. They offer a window into the Earth's infancy (e.g. Froude et al. 1983; Cavosie et al. 2019). In addition, relics of global chemical fractionation that occurred during the Hadean are recorded by extinct radionuclides, such as ${ }^{142} \mathrm{Nd}$ and ${ }^{182} \mathrm{~W}$ (e.g. Boyet et al. 2003; Touboul et al. 2012). The ${ }^{182} \mathrm{Hf}^{-182} \mathrm{~W}$ system operated during the first $50 \mathrm{Myr}$ after Solar System formation, and it is, hence, unlikely to have recorded processes depicted in our model. In contrast, the lifetime of ${ }^{146} \mathrm{Sm}-{ }^{142} \mathrm{Nd}$ system matches very well the timescale for DML crystallization and is, hence, very appropriate to help constrain the physical parameters of our models. Interestingly, most ${ }^{142} \mathrm{Nd}$ signatures point to major differentiation event(s) of the Earth around 4.3-4.4 Ga (i.e. 150-250 Ma after the Earth's formation, e.g. Saji et al. 2018, and references therein, Guitreau et al. 2019), also consistent with detrital zircon ages (e.g. Cavosie et al. 2019). On the other hand, the disappearance of SML would correspond to the start of the rock record (i.e. preservation of stable crustal blocks) between 4.0 and $3.8 \mathrm{Ga}$.

Considering that the SML crystallization is correlated with the end of major resurfacing on Earth, the comparison with Venus is quite appealing. Based on the crater population, it was suggested that the surface of Venus seems uniformly young. With absence of plate tectonics, this observation suggested that catastrophic resurfacing occurs episodically on Venus (Phillips \& Hansen 1998; Harris \& Bédard 2014; Smrekar et al. 2018). The available geodynamic models point out the importance of radioactive heating in the Venusian mantle which, correlated to the presence of a rigid stagnant lid, could have resulted in an increase of the mantle potential temperature with geological time, especially in the first 1-2 Ga (O'Rourke \& Korenaga 2012; Tosi et al. 2017). The mantle potential temperature could still be today above $1800 \mathrm{~K}$ on Venus, thus at a similar 

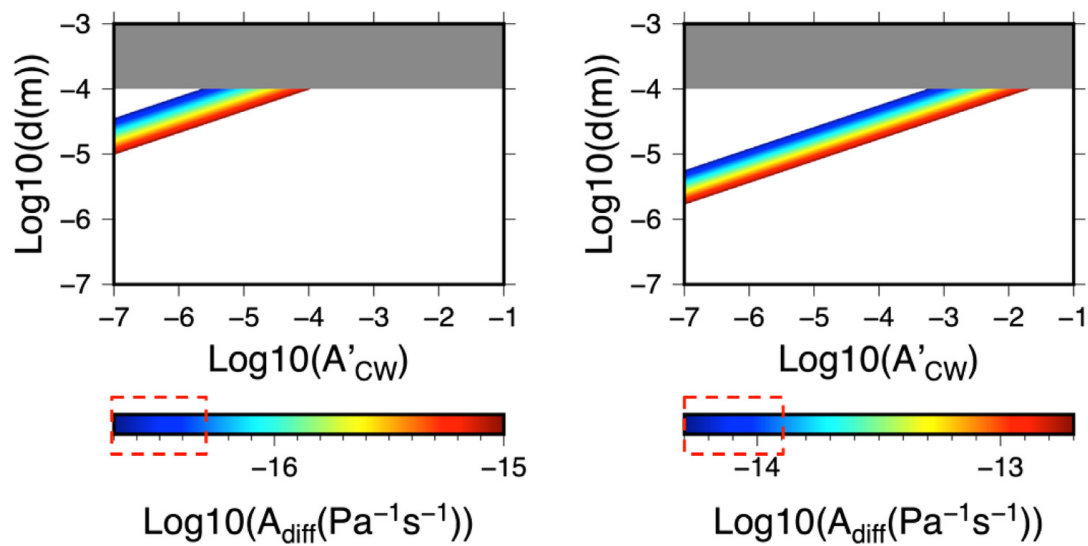

Figure 8. For the lower mantle, range of $A_{\text {diff }}$ values considered in our study for (left-hand panel) $E_{\text {diff }}=200 \mathrm{~kJ} \mathrm{~mol}^{-1}$ and (right-hand panel) $E_{\text {diff }}=300 \mathrm{~kJ}$ $\mathrm{mol}^{-1}$. The grey domain marks dislocation creep regime, below is diffusion creep regime. The white domains represent $A_{\text {diff }}$ values not considered in our study. The red dashed domains on the colour bar represent the values derived from the geological constraints.

level than it was early in the Earth's history (e.g. Herzberg et al. 2010). A logical conclusion is that partial melting still takes place today at shallow depths in the Venusian mantle.

\subsection{Refinement of mantle's rheological parameters}

Following the idea that SML and DML final crystallization correspond to identified Hadean geological events on Earth, the exact timing of these events can help refine most realistic values of $A_{\text {diff }}, E_{\text {diff }}$ and $V_{\text {diff. In our models, the upper mantle viscosity does }}$ not significantly influence the solidification time of the last global molten layers, and should not strongly affect the timing of the geological events discussed above. We cannot estimate the best pair of $E_{\text {diff }}$ and $V_{\text {diff }}$, since $V_{\text {diff }}$ has very little influence on the timing of crystallization of SML and DML. Nevertheless, we can propose a couple of solutions for fixed values of $E_{\text {diff. }}$ SML crystallization is essentially insensitive to $A_{\text {diff }}$ values and we, hence, cannot use it to estimate $A_{\text {diff }}$ values. On the other hand, the crystallization of DML is sensitive to $A_{\text {diff }}$ values. In order to explain the ages of $4.3-4.4 \mathrm{Ga}$ inferred form ${ }^{142} \mathrm{Nd}$ signatures, the lower mantle $A_{\text {diff values should }}$ range between $3 \times 10^{-17}$ and $7 \times 10^{-17} \mathrm{~Pa}^{-1} \mathrm{~s}^{-1}$ for Series 2, and $7 \times 10^{-15} \mathrm{~Pa}^{-1} \mathrm{~s}^{-1}$ to $2 \times 10^{-14}$ for Series 4 . Assuming that SML accounts for the start of the geological record (i.e. preservation of stable crustal blocks) between 4.0 and $3.8 \mathrm{Ga}$, the upper-mantle $A_{\text {diff }}$ values should range between $1 \times 10^{-9}$ and $4 \times 10^{-9} \mathrm{~Pa}^{-1} \mathrm{~s}^{-1}$. These ranges of values obtained for $A_{\text {diff }}$ in the lower and upper mantle are pretty narrow given that reference viscosities are generally unknown to multiple orders of magnitude. Moreover, the values inferred for both the lower and the upper mantle are within the range of those proposed for the mantle (Cížková et al. 2012).

\subsection{Chemical weakening and grain size}

Among the parameters used to compute the solid-state mantle viscosity the pre-exponential factor exhibits a large range of plausible values (typically two orders of magnitude). While $A_{\text {diff }}$ is called the material constant, its variability expresses the grain size sensitivity and the potential influence of chemical weakening. For olivine, this influence has been experimentally characterized for hydrogen at crustal and upper mantle pressures (e.g. Mackwell et al. 1985; Mei \& Kohlstedt 2000a, b, Demouchy et al. 2012; Girard et al. 2013; Tielke et al. 2017), for iron (Zhao et al. 2009; Hansen et al. 2012), and for titanium, (Faul et al. 2016). It can be expressed as:

$$
\frac{1}{A_{\text {diff }}}=2\left(\frac{A A_{C W}^{\prime}}{\mu}\right)^{-1}\left(\frac{b}{d}\right)^{-3},
$$

where $A$ is thus a material constant $\left(A=8.17 \times 10^{15} \mathrm{~s}^{-1}\right), \mu$ is the shear modulus $(\mu=80 \mathrm{GPa}), b$ is the magnitude of the Burgers vector $\left(b=0.55 \times 10^{-9} \mathrm{~m}\right)$ and $d$ is the grain size (Karato $\&$ Wu 1993). $A_{C W}^{\prime}$ is a dimensionless parameter characterizing the influence of the potential chemical weakening due to the incorporation of, for example $\mathrm{Al}^{3+}, \mathrm{Fe}^{2+/ 3+}, \mathrm{Ti}^{4+}$ in mantle minerals. $A_{C W}^{\prime}$ can be envisioned as a stress factor in the sense that an increase of its value leads to an increase of $A_{\text {diff }}$ and, as a consequence, to a viscosity decrease. Note that hydrogen is expected to have only very minor to negligible effect on lower mantle properties, since hydrogen can barely be embedded in bridgmanite as a point defects (Bolfan-Cavanova, Keppler \& Rubie 2003) and since the hydrogen solubility in periclase remains very limited (Bolfan-Casanova et al. 2002, see Bolfan-Casanova 2005, for a review). Therefore, 'water' weakening in the lower mantle is discarded in this study.

In our models, we have considered different values for $A_{\text {diff }}$ ranging between $2 \times 10^{-17} \mathrm{~Pa}^{-1} \mathrm{~s}^{-1}$ and $10^{-15} \mathrm{~Pa}^{-1} \mathrm{~s}^{-1}$ for $E_{\text {diff }}=200 \mathrm{~kJ}$ $\mathrm{mol}^{-1}$ and between $5 \times 10^{-15} \mathrm{~Pa}^{-1} \mathrm{~s}^{-1}$ and $2 \times 10^{-13} \mathrm{~Pa}^{-1} \mathrm{~s}^{-1}$ for $E_{\text {diff }}=300 \mathrm{~kJ} \mathrm{~mol}^{-1}$. According to eq. (20), each value of $A_{\text {diff }}$ corresponds to a set of values for the pair $d$ and $A_{C W}^{\prime}$. In Fig. 8, we plotted $A_{\text {diff }}$ as a function of $d$ and $A_{C W}^{\prime}$. From Fig. 8, we can estimate the range of plausible values for $d$ and $A_{C W}^{\prime}$ corresponding to the values of $A_{\text {diff }}$ considered in our models. The transition from diffusion to dislocation creep is expected to occur for $d$ larger than $100 \mu \mathrm{m}$ in the lower mantle (Boioli et al. 2017). Considering only a domain where the diffusion creep scaling applies, Fig. 8 illustrates that $d$ ranges between 10 and $100 \mu \mathrm{m}$ for $E_{\mathrm{diff}}=200 \mathrm{~kJ} \mathrm{~mol}^{-1}$ and between 1 and $100 \mu \mathrm{m}$ for $E_{\text {diff }}=300 \mathrm{~kJ} \mathrm{~mol}^{-1}$. In the mean time, $A_{C W}^{\prime}$ ranges between $10^{-7}$ and $10^{-4}$ for $E_{\text {diff }}=200 \mathrm{~kJ} \mathrm{~mol}^{-1}$ and between $10^{-7}$ and $10^{-2}$ for $E_{\text {diff }}=300 \mathrm{~kJ} \mathrm{~mol}^{-1}$. Fig. 8 shows that when increasing the grain size by a factor 10 , the stress factor associated to chemical weakening has to be increased by a factor 1000 to maintain a constant pre-exponential factor $A_{\text {diff }}$.

Our arguments developed in previous sections suggest the following range for $A_{\text {diff }}$ values within the lower mantle: between $3 \times 10^{-17}$ and $7 \times 10^{-17} \mathrm{~Pa}^{-1} \mathrm{~s}^{-1}$ for $E_{\text {diff }}=200 \mathrm{~kJ} \mathrm{~mol}^{-1}$, and between $7 \times 10^{-15} \mathrm{~Pa}^{-1} \mathrm{~s}^{-1}$ and $2 \times 10^{-14} \mathrm{~Pa}^{-1} \mathrm{~s}^{-1}$ for $E_{\text {diff }}=300 \mathrm{~kJ} \mathrm{~mol}^{-1}$, 
based on the comparison between our models and geological features. When reporting these two ranges of values in Fig. 8, we illustrate that these values correspond to the material colored within the red dashed box. Using eq. (20), we can relate our preferred values for $A_{\text {diff }}$ and the grain size that prevailed in the deep mantle during this period. Hence we can constrain $d$ between 30 and $100 \mu \mathrm{m}$ when $E_{\text {diff }}=200 \mathrm{~kJ} \mathrm{~mol}^{-1}$ and between 3 and $100 \mu \mathrm{m}$ when $E_{\text {diff }}=300 \mathrm{~kJ}$ $\mathrm{mol}^{-1}$. In the meantime, from our models, the dimensionless parameter characterizing the influence of the chemical weakening $A_{C W}^{\prime}$ would range between $10^{-7}$ and $10^{-5}$ when $E_{\text {diff }}=200 \mathrm{~kJ} \mathrm{~mol}^{-1}$ and between $10^{-7}$ and $10^{-3}$ when $E_{\text {diff }}=300 \mathrm{~kJ} \mathrm{~mol}^{-1}$. Therefore, constraining the $E_{\text {diff }}$ values in the deep mantle from geological features could help to reduce the range of potential stress factor related to chemical weakening and grain size within the deep mantle.

\subsection{Model limitations}

1-D models are appropriate to characterize the first order cooling and solidification dynamics of a compressible mushy mantle where viscosity contrasts between solid mantle and magmas can reach up to 20 orders of magnitude. However, we acknowledge that the timescales for SML and DML crystallization may be affected by $3-$ D lateral variations. The early geotherms obtained from our models can be implemented in geometrically more realistic models developed to characterize the global geodynamic regime that operated prior to the onset of modern plate tectonics (Rozel et al. 2017; Agrusta et al. 2018).

The surface temperature and the ability of the top boundary layer to facilitate the heat loss are key parameters that also control the cooling dynamics of the mushy mantle. In our study we have assumed that the surface temperature was constant $(=500 \mathrm{~K})$ according to Lebrun et al. (2013) and Sleep et al. (2014). However, this surface temperature may be overestimated, as the dissolution of $\mathrm{CO}_{2}$ in the condensed water is not accounted. In addition, depending on the buoyancy of the residual melt, partial melting in the shallow melt layer is likely to rise towards the surface through magma conduits and cool the interior efficiently by volcanic heat transport (Ricard et al. 2014; Kankanamge \& Moore 2019). Both these shallow processes may enhance the heat evacuation and affect the timescales and depths obtained in our study.

The chemical differentiation that is not accounted in our models could affect the results obtained from our models by different ways.

(1) The vertical chemical segregation due to compatible/incompatible elements separation could be an important feature during this early cooling event (Ballmer et al. 2017) and could delay the solidification. Such a vertical segregation depends on the possible occurrence of gravitational fractionation of the Fe-enriched melt and the solid in a turbulent magma ocean.

(2) Considering a chemical differentiation between compatible/incompatible elements would also affect the partitioning of radiogenic heat producing elements. Indeed, $\mathrm{K}$, Th and $\mathrm{U}$ are incompatible elements which will accumulate preferentially in the molten reservoirs. Hence the chemical segregation is likely to affect the heat partitioning within the mantle and as a consequence its cooling dynamics.

(3) During the chemical segregation, the composition of the molten phase will evolve towards an enrichment in incompatible elements. This chemical evolution will affect the melting curves (Andrault et al. 2017)

\section{CONCLUSION}

We have performed 1-D numerical simulations to monitor the temperature and melt fraction evolutions of an initially $40 \%$ molten early mantle. In our models, we have implemented recent and solid experimental constraints from mineral physics. We have considered a range of solid fraction viscosity compatible with the knowledge of the current lowermost mantle viscosity. Our models illustrate the influence of the solid mantle fraction viscosity on the cooling of a deep mushy mantle, and in particular on the characteristic time and depth at which complete solidification is achieved. Considering that deformation occurs via diffusion creep, the cooling dynamics is mainly governed by the pre-exponential factor $A_{\text {diff. }}$ Our models highlight two molten layers (SML and DML) whose complete crystallization are separated both in time and space: DML solidifying earlier (between 40 and $400 \mathrm{Ma}$ ) and deeper (between 800 and $1200 \mathrm{~km}$ ) than SML, whose solidification occurs during the first 400-800 Ma, and at depth ranging between 30 and $50 \mathrm{~km}$. The viscosity of the upper mantle plays a key role on the time and depth of solidification of the shallow SML, whereas the viscosity of the deep mantle governs the duration of DML solidification.

The solidification timescales derived from our models suggest a full crystallization of the early mantle at the Hadean-Eoarchean boundary. A shallow molten layer stable during 150-250 Ma after the Earth's formation could favor the absence of early reliefs and isolate the early crust from the underlying mantle dynamics. We associate the crystallization of SML and DML to major events in the geological record. Then, we use the timing of these records to refine a preferred set of parameters defining the mantle viscosity. Our models favor the highest values of the range of deep mantle viscosities derived from geoid inversion and post-glacial rebound (Čížková et al. 2012, and references therein). From our preferred viscosity models, our study suggests a $3-100 \mu \mathrm{m}$ range for grain size and a chemical weakening parameter ranging between $10^{-7}$ and $10^{-3}$. Our 1-D approach is relevant when characterizing a fully mushy early mantle where large viscosity contrasts associated to large Rayleigh numbers can persist during the whole solidification of the reservoir. The temperature profiles and the TBLs characteristics inferred from our study can easily be incorporated in thermochemical evolution models of a solid terrestrial mantle.

\section{ACKNOWLEDGEMENTS}

The authors thank Maud Boyet, Craig Storey and Hugo Moreira for fruitful discussions. The authors also thank J. Roberts and anonymous reviewer for thoughtful and constructive comments. The authors also thank G. Tobie and B. Cecconi for their useful help in the development of the numerical model. This is ClerVolc contribution number 400. H. S. acknowledges the support from the "Deutsche Forschungsgemeinschaft" (grant number SA 2042/3-1).

\section{References}

Abe, Y., 1997. Thermal and chemical evolution of the terrestrial magma ocean, Phys. Earth planet. Inter, 100, 27-39.

Agrusta, R., van Hunen, J. \& Goes, S., 2018. Strong plates enhance mantle mixing in early Earth, Nature Communications, 9, 2708.

Andrault, D., Bolfan-Casanova, N., Lo Nigro, G., Bouhifd, M.A., Garbarino, G. \& Mezouar, M., 2011. Melting curve of the deep mantle applied to properties of early magma ocean and actual core-mantle boundary, Earth planet. Sci. Lett., 304, 251-259.

Andrault, D., et al., 2018. Deep and persistent melt layer in the Archaean mantle, Nat. Geosci., 11, 139-143, doi:10.1038/s41561-017-0053-9. 
Andrault, D. et al., 2017. Toward a coherent model for the melting behaviour of the deep Earth's mantle, Phys. Earth planet. Inter., 265, 67-81.

Ballmer, M.D., Lourenço, D.L., Hirose, K., Caracas, R. \& Nomura, R., 2017. Reconciling magma-ocean crystallization models with the presentday structure of the Earth's mantle, Geochem. Geophys. Geosyst., 18, 2785-2806.

Boioli, F., Carrez, P., Cordier, P., Devincre, B., Gouriet, K., Hirel, P., Kraych, A. \& Ritterbex, S., 2017. Pure climb creep mechanism drives flow in the Earth's lower mantle, Sci. Adv, 3, e1601958, doi: 10.1126/sciadv. 1601958 .

Bolfan-Casanova, N., 2005. Water in the Earth's mantle, Mineral. Mag., 69, 3, 229-257.

Bolfan-Casanova, N., Keppler, H. \& Rubie, D., 2003. Water partitioning at $660 \mathrm{~km}$ depth and evidence for very low water solubility in magnesium silicate perovskite. Geophys. Res. Lett., 30, doi: 10.1029/2003GL017182.

Bolfan-Casanova, N., Mackwell, S., Keppler, H., McCammon, C. \& Rubie, D., 2002. Pressure dependence of h solubility in magnesiowustite up to $25 \mathrm{GPa}$ : Implications for the storage of water in the Earth's lower mantle, Geophys. Res. Lett., 29, 1449, 1-4.

Boukare, C.E., Ricard, Y. \& Fiquet, G., 2015. Thermodynamics of the MgO$\mathrm{FeO}-\mathrm{SiO}_{2}$ system up to $140 \mathrm{GPa}$ : application to the crystallization of Earth's magma ocean, J. geophys. Res., 120, 6085-6101.

Bower, D.J., Sanan, P. \& Wolf, A.S., 2018. Numerical solution of a nonlinear conservation law applicable to the interior dynamics of partially molten planets, Phys. Earth planet. Inter., 274, 49-62.

Boyet, M., Blichert-Toft, J., Rosing, M., Storey, M., Télouk, P. \& Albarède, F., 2003. 142Nd evidence for early Earth differentiation, Earth planet. Sci. Lett. 214, 427-442.

Boyet, M. \& Carlson, R.W., 2005. 142Nd evidence for early (>4.53 Ga) global differentiation of the silicate Earth, Science 309, 576-581.

Cavosie, A.J., Valley, J.W. \& Wilde, S.A., 2019. The oldest terrestrial mineral record: Thirty years of research on Hadean zircon from Jack Hills, Western Australia, in: Earth's Oldest Rocks, 2nd edn, Chapter 12, pp. 255-278, eds Van Kranendonk, M.J. Bennett, V.C. \& Hoffmann, J.E., Elsevier.

Choblet, G. \& Sotin, C., 2000. 3D thermal convection with variable viscosity: can transient cooling be described by a quasi-static scaling law?, Phys. Earth planet. Inter. 119, 321-336.

Cochain, B., Sanloup, C., Leroy, C. \& Kono, Y., 2017. Viscosity of mafic magmas at high pressures, Geophys. Res. Lett., 44(2), 818-826.

Crank, J., 1975. The Mathematics of Diffusion, 2nd edn, Clarendon Press. viii, $414 \mathrm{p}$.

Ćížková, H., van den Berg, A.P., Spakman, W. \& Matyska, C., 2012. The viscosity of Earth's lower mantle inferred from sinking speed of subducted lithosphere, Phys. Earth Planet. Inter., 200-201, 56-62.

Demouchy, S., Tommasi, A., Barou, F., Mainprice, D. \& Cordier, P., 2012. Deformation of olivine in torsion under hydrous conditions, Phys. Earth planet. Inter, 202-203, 56-70.

Deschamps, F. \& Sotin, C., 2000. Inversion of two-dimensional numerical convection experiments for a fluid with a strongly temperature-dependent viscosity, Geophys. J. Int., 143, 204-218.

Doglioni, C., Ismail-Zadeh, A., Panza, G. \& Riguzzi, F., 2011. Lithosphereasthenosphere viscosity contrast and decoupling, Phys. Earth planet. Inter., 189, 1-8.

Faul, U.H., Cline, C.J., David, E.C. \& Jackson, I., 2016. Titanium-hydroxyl defect-controlled rheology of the Earth's upper mantle, Earth planet. Sci. Lett., 452, 227-237.

Fiquet, G., Auzende, A.L., Siebert, J., Corgne, A., Bureau, H., Ozawa, H. \& Garbarino, G., 2010. Melting of Peridotite to 140 Gigapascals, Science, 329, 1516-1518.

Foley, B.J., Bercovici, D. \& Elkins-Tanton, L.T., 2014. Initiation of plate tectonics from post-magma ocean thermochemical convection, J. geophys. Res., 119, 8538-8561.

Frost, H.J. \& Ashby, M.F., 1982, Deformation-Mechanism Maps: The Plasticity and Creep of Metals and Ceramics, Pergamon, Oxford.

Froude, D.O., Ireland, T.R., Kinny, P.D., Williams, I.S. \& Compston, W., 1983. Ion microprobe identification of 4,100-4,200 Myr-old terrestrial zircons, Nature, 304, 616-618.
Girard, J., Chen, J., Raterron, P. \& Holyoke, C.W., 2013. Hydrolytic weakening of olivine at mantle pressure: Evidence of [100](010) slip system softening from single-crystal deformation experiments. 1-9.

Goodwin, A.M., 1996. Principles of Precambrian Geology, pp. 327, Academic Press.

Grott, M. \& Breuer, D., 2008, The evolution of the martian elastic lithosphere and implications for crustal and mantle rheology, Icarus, 193, 503-515.

Guitreau, M., Blichert-Toft, J., Martin, H., Mojzsis, S.J. \& Albarède, F., 2012. Hafnium isotope evidence from Archean granitic rocks for deep mantle origin of continental crust, Earth planet. Sci. Lett., 337-338, 211-223.

Guitreau, M., Boyet, M., Paquette, J.-L., Gannoun, A., Konc, Z., Benbakkar, M., Suchorski, K. \& Hénot, J.-M., 2019, Hadean protocrust reworking at the origin of the Archean Napier Complex (Antarctica), Geochem. Perspect. Lett., 12, 7-11.

Hansen., L.N., Zimmerman, M.E. \& Kohlstedt, D.L., 2012. The influence of microstructure on deformation of olivine in the grain-boundary sliding regime., J. geophys.Res., 117, B09201, doi: 10.1029/2012JB009305.

Harris, L. \& Bédard, J., 2014. Modern approaches in solid earth sciences, in Evolution of Archean Crust and Early Life, Vol. 7, Chapter 9, pp. 215-288, eds Dilek, Y. \& Furnes, H., Springer.

Herzberg, C., Condie, K. \& Korenaga, J., 2010. Thermal history of the Earth and its petrological expression, Earth planet. Sci. Lett., 292, 79-88.

Hirth, G. \& Kohlstedt, D.L., 2003. Rheology of the upper mantle and the mantle wedge: a review from the experimentalists, in Inside the Subduction Factory, Geophys. Monogr. Ser., Vol. 138, pp. 83-105, ed. Eiler, J., AGU.

Huet, B., Yamato, P. \& Grasemann, B., 2014. The minimized power geometric model: an analytical mixing model for calculating polyphase rock viscosities consistent with experimental data, J. geophys. Res., 119, 3897-3924.

Javoy, M., 1999. Chemical earth models, C. R. Acad. Sci. Paris, 329, $537-$ 555 .

Javoy, M. et al., 2010. The chemical composition of the Earth: Enstatite chondrite models, Earth planet. Sci. Lett., 293, 259-268.

Ji, S., Wang, Z. \& Wirth, R., 2001. Bulk flow strength of Forsterite-Enstatite composites as a function of forsterite content, Tectonophysics, 341, 69-93.

Kankanamge, D.G.J. \& Moore, W.B., 2019. A parameterization for volcanic heat flux in heat pipe planets, J. geophys. Res., 124, 114-127.

Karato, S., \& Li, P., 1992. Diffusion creep in perovskite: Implications for the rheology of the lower mantle, Science, 255, 1238-1240, doi:10.1126/ science.255.5049.1238.

Karato, S.I. \& Wu, P., 1993. Rheology of the upper mantle: a synthesis, Science, 260, 771-778.

Karki, B.B. \& Stixrude, L.P., 2010. Viscosity of $\mathrm{MgSiO}_{3}$ liquid at Earth's mantle conditions: implications for an early magma ocean, Science, $\mathbf{3 2 8}$, 740-742.

Laneuville, M., Hernlund, J., Labrosse, S. \& Guttenberg, N., 2018. Crystallization of a compositionally stratified basal magma ocean, Phys. Earth planet. Inter., 276, 86-92.

Lebrun, T., Massol, H., Chassefiere, E., Davaille, A., Marcq, E., Sarda, P., Leblanc, F. \& Brandeis, G., 2013. Thermal evolution of an early magma ocean in interaction with the atmosphere, J. geophys. Res., 118, 11551176.

Mackwell, S.J., Kohlstedt, D.L. \& Paterson, M.S., 1985. The role of water in the deformation of olivine single crystals, J. Geophys. Res., 90, 1131911333.

McDonough, W. \& Sun, S.-s., 1995. The composition of the Earth, Chem. Geol., 120(3-4), 223-253.

Mei, S., Bai, W., Hiraga, T. \& Kohlstedt, D.L., 2002. Influence of melt on the creep behavior of olivine-basalt aggregates under hydrous conditions, Earth planet. Sci. Lett., 201, 491-507.

Mei, S. \& Kohlstedt, D.L., 2000a. Influence of water on plastic deformation of olivine aggregates 2. Dislocation creep regime, J. geophys. Res., 105, $21471-21481$

Mei, S. \& Kohlstedt, D.L., 2000b. Influence of water on the plastic deformation of olivine aggregates: 1. Diffusion creep regime, J. geophys. Res., 105, $21457-21469$. 
Monteux, J., Andrault, D. \& Samuel, H., 2016. On the cooling of a deep terrestrial magma ocean, Earth planet. Sci. Lett., 448, 140-149.

Mosenfelder, J.L., Asimow, P.D. \& Ahrens, T.J., 2007. Thermodynamic properties of $\mathrm{Mg}_{2} \mathrm{SiO}_{4}$ liquid at ultra-high pressures from shock measurements to $200 \mathrm{GPa}$ on forsterite and wadsleyite, J. geophys. Res., 112, B06208, doi:10.1029/2006JB004364.

Mosenfelder, J.L., Asimow, P.D., Frost, D.J., Rubie, D.C. \& Ahrens, T.J., 2009. The $\mathrm{MgSiO}_{3}$ system at high pressure: thermodynamic properties of perovskite, post-perovskite, and melt from global inversion of shock and static compression data, J. geophys. Res., 114, B01203.

Nakajima, M. \& Stevenson, D.J., 2015. Melting and mixing states of the Earth's mantle after the Moon-forming impact, Earth planet. Sci. Lett., 427, 286-295.

O'Rourke, J.G. \& Korenaga, J., 2012. Terrestrial planet evolution in the stagnant-lid regime: size effects and the formation of self-destabilizing crust, Icarus, 221, 1043-1060.

Palme, H. \& O'Neill, H., 2014. Cosmochemical estimates of mantle composition, in ed. Treatise on Geochemistry, 2nd edn, Vol. 3. pp. 1-39, ed. Carlson, R.W., Elsevier.

Phillips, R.J. \& Hansen, V.L., 1998, Geological evolution of Venus: rises, plains, plumes and plateaus, Science, 279, 1492-1497.

Press, W.H., Teukolsky, S.A., Vetterling, W.T. \& Flannery, B.P., 1993. Numerical Recipes in FORTRAN the Art of Scientific Computing, 2nd edn. Cambridge Univ. Press.

Reali, R., van Orman, J., Pigott, J., Jackson, J.M., Boioli, F., Carrez, P. \& Cordier, P., 2019. The role of diffusion-driven pure climb creep on the rheology of bridgmanite under lower mantle conditions, Sci. Rep., 9, 2053.

Ricard, Y., Labrosse, S. \& Dubuffet, F., 2014. Lifting the cover of the cauldron: convection in hot planets, Geochem. Geophys. Geosyst., 15, $4617-4630$.

Roscoe, R., 1952. The viscosity of suspensions of rigid spheres, Br. J. Appl. Phys., 3, 267-269.

Rozel, A.B., Golabek, G.J., Jain, C., Tackley, P.J. \& Gerya, T., 2017. Continental crust formation on early Earth controlled by intrusive magmatism, Nature, 545, 332-335.

Rubie, D.C. et al., 2011. Heterogeneous accretion, composition and coremantle differentiation of the Earth, Earth planet. Sci. Lett., 301, 31-42.

Saji, N.S., Larsen, K., Wielandt, D., Schiller, M., Costa, M.M., Whitehouse, M.J., Rosing, M.T. \& Bizzarro, M., 2018. Hadean geodynamics inferred from time-varying $142 \mathrm{Nd} / 144 \mathrm{Nd}$ in the early Earth rock record, Geochem.. Perspect. Lett., 7, 43-48, doi:10.7185/geochemlet.1818.

Sawyer, E.W., Cesare, B. \& Brown, M., 2011. When the continental crust melts, Elements, 7, 229-234.

Simon, F. \& Glatzel, G., 1929. Fusion-pressure curve, Z. Anorg. Allg. Chem., 178, 309.

Sleep, N.H., Zahnle, K.J. \& Lupu, R.E., 2014. Terrestrial aftermath of the Moon-forming impact, Philos. Trans. R. Soc. A, 372, doi:10.1098/rsta.2013.0172.

Smrekar, S., Davaille, A. \& Sotin, C., 2018. Venus interior structure and dynamics, Space Sci. Rev., 214(5), 88, 34 pp.

Solomatov, V., 1995. Scaling of temperature-and stress-dependent viscosity convection, Phys. Fluids, 7, 266.

Solomatov, V., 2007. Magma Oceans and Primordial Mantle Differentiation, in Treatise of Geophysics, Vol. 9, ed. Schubert, G., Elsevier.

Solomatov, V.S., 2000. Fluid dynamics of terrestrial magma ocean, in Origin of the Earth and Moon, pp. 323-338, eds Canup, R.M. \& Righter, K., The University of Arizona Press.

Solomatov, V.S., 2015, Magma oceans and primordial mantle differentiation, in Treatise on Geophysics, 2nd edn., pp. 81-104, ed. Schubert, G., Elsevier, Amsterdam.

Tackley, P.J., 2012. Dynamics and evolution of the deep mantle resulting from thermal, chemical, phase and melting effects, Earth Sci. Rev., 110, $1-25$.

Thiriet, M., Breuer, D., Michaut, C. \& Plesa, A.-C., 2019. Scaling laws of convection for cooling planets in a stagnant lid regime, Phys. Earth planet. Inter., 286, 138-153.

Thomas, C.W. \& Asimow, P.D., 2013. Direct shock compression experiments on premolten forsterite and progress toward a consistent high-pressure equation of state for $\mathrm{CaO}-\mathrm{MgO}-\mathrm{Al}_{2} \mathrm{O}_{3}-\mathrm{SiO}_{2}-\mathrm{FeO}$ liquids, J. geophys. Res., 118, 5738-5752.

Thomas, C.W., Liu, Q., Agee, C.B., Asimow, P.D. \& Lange, R.A., 2012. Multi-technique equation of state for $\mathrm{Fe} 2 \mathrm{SiO} 4$ melt and the density of Febearing silicate melts from 0 to $161 \mathrm{GPa}, J$. Geophys. Res., Solid Earth, 117, B10206, doi:10.1029/2012JB009403.

Tielke, J.A., Zimmerman, M.E. \& Kohlstedt, D.L. 2017. Hydrolytic weakening in olivine single crystals, J. geophys. Res., 122, 3465-3479.

Tosi, N. et al., 2017. The habitability of a stagnant-lid Earth, Astron. Astrophys., 605, A71.

Touboul, M., Puchtel, I.S. \& Walker, R.J., 2012. 182W evidence for longterm preservation of early mantle differentiation products, Science, $\mathbf{3 3 5}$, $1065-1069$

Ulvrová, M., Labrosse, S., Coltice, N., Råback, P. \& Tackley, P.J., 2012. Numerical modelling of convection interacting with a melting and solidification front: application to the thermal evolution of the basal magma ocean, Phys. Earth Planet. Inter, 206, 51-66, http://dx.doi.org/10.1016/j.pepi.2012.06.008.

Wagner, F.W., Plesa, A.C. \& Rozel, A.B., 2019. Calibrating mixing-length theory for thermal convection in rocky planets, Geophys. J. Int., 217, $75-89$.

Xu, J., Yamazaki, D., Katsura, T., Wu, X., Remmert, P., Yurimoto, H. \& Chakraborty, S., 2011. Silicon and magnesium diffusion in a single crystal of $\mathrm{MgSiO}_{3}$ perovskite, $J$ geophys. Res., 116, B12205, doi: 10.1029/2011JB008444.

Zhao, Y.H, Zimmerman, M.E. \& Kohlstedt, D.L. 2009. Effect of iron content on the creep behavior of olivine, 1: anhydrous conditions, Earth planet. Sci. Lett., 287 (1), 229-240.

\section{APPENDIX: NUMERICAL BENCHMARK OF THE ENERGY BALANCE EQUATION}

We validated our numerical approach by benchmarking our model with the analytical non-steady state diffusion problem (eq 6.18 in the section 6. Diffusion in a sphere from Crank 1975) and obtained a relative error below $10^{-7}$. We also benchmarked our physical approach by comparing our model with those developed for modeling convection in rocky planets from Wagner et al. (2019). In particular, we considered the same setting used to obtain their Fig. 8(a) where they $\mathrm{Ra}=10^{7}$ and they impose a viscosity contrast of 100 between the top and the bottom of the mantle. This comparison is illustrated in Fig. A1.

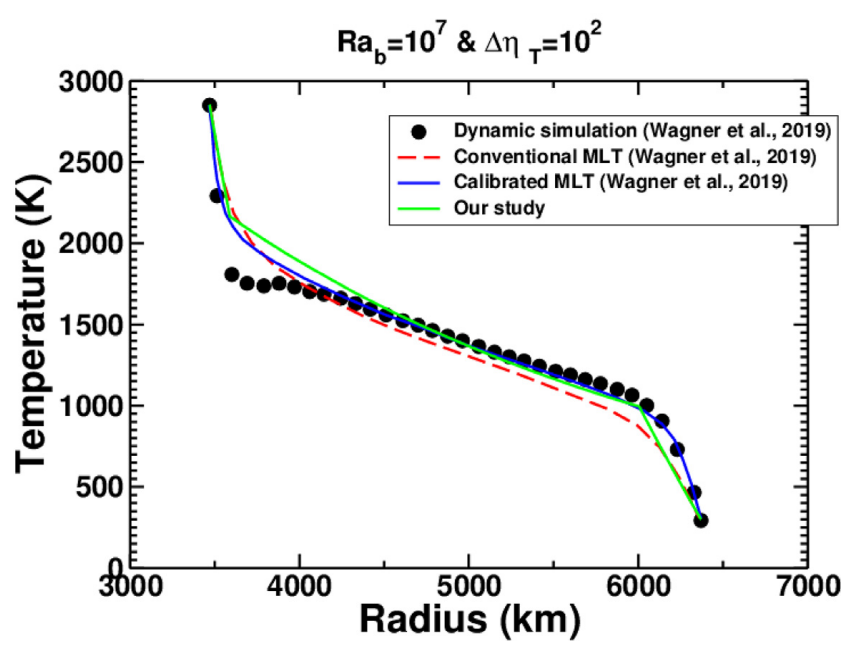

Figure A1. Comparison of the temperature profiles obtained by Wagner et al. 2019 (Fig. 8a from their study) (black dots, red dashed line and solid blue line) and the temperature profile obtained from our 1-D model with the same parametrization $\left(\mathrm{Ra}=10^{7}\right.$ and a viscosity contrast of 100$)$. 
Fig. A1 shows that our results reasonably agree with spherical calculations displayed in the study quoted above, which confirms that our approach can reproduce the thermal evolution in non-symmetric spherical geometry. Moreover, Fig. A1 shows that our results are in agreement with the 1-D (Mixing Length Theory) approach and the evolutions computed in spherical geometry by Wagner et al. (2019). Differences between our approach and the MLT approach by Wagner et al. (2019) are due to different parametrization details. Moreover, as we impose a conductive heat flux within the two
TBLs, it leads to a change in the temperature profile between the convective mantle, and the conductive TBL that is less smooth than in the models from Wagner et al. (2019). In the two TBL, the error between our models and the models from Wagner et al. (2019) can reach $\approx 20 \%$ while in the central parts of the mushy mantle, the error is less than 5\%. However, for larger values of Ra numbers that are more relevant to our study, the TBL are considerably thinner, therefore these differences are expected to vanish. 